\title{
Occurrence of halogenated flame retardants in commercial seafood species available
} in European markets

\author{
Aznar-Alemany, Òscar; Trabalón, Laura; Jacobs, Silke; Barbosa, Vera Liane; Tejedor, Margarita \\ Fernández; Granby, Kit; Kwadijk, Christiaan; Cunha, Sara C.; Ferrari, Federico; Vandermeersch, Griet \\ Total number of authors: \\ 16
}

Published in:

Food and Chemical Toxicology

Link to article, DOI:

10.1016/j.fct.2016.12.034

Publication date:

2017

Document Version

Peer reviewed version

Link back to DTU Orbit

Citation (APA):

Aznar-Alemany, Ò., Trabalón, L., Jacobs, S., Barbosa, V. L., Tejedor, M. F., Granby, K., Kwadijk, C., Cunha, S. C., Ferrari, F., Vandermeersch, G., Sioen, I., Verbeke, W., Vilavert, L., Domingo, J. L., Eljarrat, E., \& Barceló, D. (2017). Occurrence of halogenated flame retardants in commercial seafood species available in European markets. Food and Chemical Toxicology, 104, 35-47. https://doi.org/10.1016/j.fct.2016.12.034

\section{General rights}

Copyright and moral rights for the publications made accessible in the public portal are retained by the authors and/or other copyright owners and it is a condition of accessing publications that users recognise and abide by the legal requirements associated with these rights.

- Users may download and print one copy of any publication from the public portal for the purpose of private study or research.

- You may not further distribute the material or use it for any profit-making activity or commercial gain

- You may freely distribute the URL identifying the publication in the public portal 


\section{Accepted Manuscript}

Occurrence of halogenated flame retardants in commercial seafood species available in European markets

Òscar Aznar-Alemany, Laura Trabalón, Silke Jacobs, Vera Liane Barbosa, Margarita Fernández Tejedor, Kit Granby, Christiaan Kwadijk, Sara C. Cunha, Federico Ferrari, Griet Vandermeersch, Isabelle Sioen, Wim Verbeke, Lolita Vilavert, José L. Domingo, Ethel Eljarrat, Damià Barceló

PII: S0278-6915(16)30495-1

DOI: 10.1016/j.fct.2016.12.034

Reference: $\quad$ FCT 8841

To appear in: Food and Chemical Toxicology

Received Date: 27 June 2016

Revised Date: 19 December 2016

Accepted Date: 23 December 2016

Please cite this article as: Aznar-Alemany, E., Trabalón, L., Jacobs, S., Barbosa, V.L., Tejedor, M.F., Granby, K., Kwadijk, C., Cunha, S.C., Ferrari, F., Vandermeersch, G., Sioen, I., Verbeke, W., Vilavert, L., Domingo, J.L., Eljarrat, E., Barceló, D., Occurrence of halogenated flame retardants in commercial seafood species available in European markets, Food and Chemical Toxicology (2017), doi: 10.1016/ j.fct.2016.12.034.

This is a PDF file of an unedited manuscript that has been accepted for publication. As a service to our customers we are providing this early version of the manuscript. The manuscript will undergo copyediting, typesetting, and review of the resulting proof before it is published in its final form. Please note that during the production process errors may be discovered which could affect the content, and all legal disclaimers that apply to the journal pertain. 
Occurrence of halogenated flame retardants in commercial seafood species available in

\section{European markets}

Òscar Aznar-Alemany ${ }^{a}$, Laura Trabalón ${ }^{b}$, Silke Jacobs ${ }^{c, d}$, Vera Liane Barbosa ${ }^{e}$, Margarita Fernández Tejedor ${ }^{\mathrm{f}}$, Kit Granby ${ }^{\mathrm{g}}$, Christiaan Kwadijk ${ }^{\mathrm{h}}$, Sara C. Cunhai, Federico Ferrari ${ }^{\mathrm{j}}$, Griet Vandermeersch $^{k}$, Isabelle Sioen ${ }^{c, l}$, Wim Verbeke ${ }^{d}$, Lolita Vilavert $^{m}$, José L. Domingo ${ }^{m}$, Ethel Eljarrat $^{\mathrm{a}, *}$, Damià Barceló ${ }^{\mathrm{a}, \mathrm{n}}$

${ }^{a}$ Institute of Environmental Assessment and Water Research, Department of Environmental Chemistry (IDAEA-CSIC). Jordi Girona, 18, 08034 Barcelona (Spain)

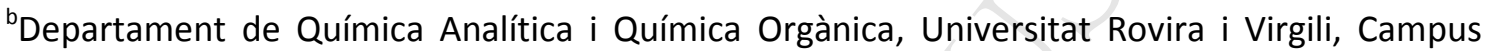
Sescelades, Marcel·lí Domingo, s/n, 43007 Tarragona, Catalonia, Spain

'Department of Public Health, Ghent University, UZ 4K3, De Pintelaan 185, 9000 Ghent, Belgium

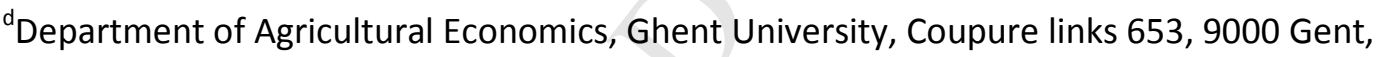
Belgium

${ }^{e}$ Division of Aquaculture and Seafood Upgrading. Portuguese Institute for the Sea and Atmosphere, I.P. (IPMA). Avenida de Brasília, 1449-006 Lisbon, Portugal

fInstitute of Agrifood Research and Technology (IRTA). Ctra. de Poble Nou, Km 5,5; E-43540 Sant Carles de la Ràpita, Spain

${ }^{\mathrm{g}}$ Technical University of Denmark, National Food Institute, Moerkhoej Bygade 19, DK2830 Soeborg, Denmark

${ }^{\mathrm{h}}$ Institute for Marine Resources and Ecosystem Studies (IMARES). Wageningen UR, PO Box 68, 1970 AB ljmuiden, The Netherlands 
'LaQV-REQUIMTE, Laboratory of Bromatology and Hydrology, Faculty of Pharmacy, University of Porto, Rua Jorge de Viterbo Ferreira 228, 4050-313 Porto, Portugal

jAeiforia Srl. Località Faggiola 16, 29027 Gariga di Podenzano (Piacenza), Italy

${ }^{k}$ Institute for Agricultural and Fisheries Research (ILVO), Animal Sciences Unit - Fisheries, Ankerstraat 1, 8400 Oostende, Belgium

'Department of Food Safety and Food Quality, Ghent University, Block B, Coupure Links 653, 9000 Ghent, Belgium

mLaboratory of Toxicology and Environmental Health, School of Medicine, IISPV, Universitat Rovira i Virgili, Sant Llorenç 21, 43201 Reus, Catalonia, Spain

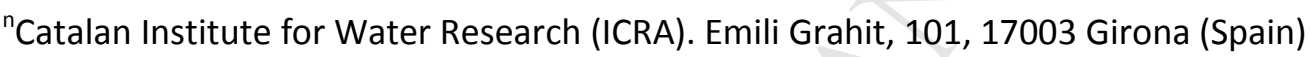

oaaqam@cid.csic.es

laura.trabalon@urv.cat

silke.jacobs@ugent.be

vera.barbosa@ipma.pt

margarita.fernandez@irta.cat

kgra@food.dtu.dk

christiaan.kwadijk@wur.nl

sara.cunha@ff.up.pt 
federico.ferrari@aeiforia.it

griet.vandermeersch@ilvo.vlaanderen.be

isabelle.sioen@ugent.be

wim.verbeke@ugent.be

lolita.vilavert@urv.cat

joseluis.domingo@urv.cat

eeeqam@cid.csic.es

dbcqam@cid.csic.es

Corresponding author: Ethel Eljarrat, eeeqam@cid.csic.es, tel: +34 93400 6100, fax: +34 93 204 5904. Carrer de Jordi Girona, 18-26, 08034 Barcelona (Spain) 


\section{Abstract}

PBDEs (congeners $28,47,99,100,153,154,183,209)$, $\operatorname{HBCD}(\alpha, \beta, \gamma)$, emerging brominated flame retardants (PBEB, HBB and DBDPE), dechloranes (Dec 602, 603, 604, syn- and anti-DP), TBBPA, 2,4,6-TBP and MeO-PBDEs (8 congeners) were analysed in commercial seafood samples from European countries. Levels were similar to literature and above the environmental quality standards (EQS) limit of the Directive 2013/39/EU for PBDEs. Contaminants were found in $90.5 \%$ of the seafood samples at n. d. $-356 \mathrm{ng} / \mathrm{g}$ lw (n. d.-41.1 ng/g ww). DBDPE was not detected and 2,4,6-TBP was detected only in mussels, but at levels comparable to those of PBDEs. Mussel and seabream were the most contaminated species and the Mediterranean Sea (FAO Fishing Area 37) was the most contaminated location. The risk assessment revealed that there was no health risk related to the exposure to brominated flame retardants via seafood consumption. However, a refined risk assessment for BDE-99 is of interest in the future. Moreover, the cooking process concentrated PBDEs and HBB.

Keywords: effect of cooking; margin of exposure; PBDEs; risk assessment; 2,4,6-TBP 


\section{Funding sources:}

European Union Seventh Framework Programme (FP7/2007-2013) under the ECsafeSEAFOOD project (grant agreement $n^{\circ} 311820$ ): Involved in the whole process, i. e. in study design, in the collection, in the writing of the report, and in the decision to submit the article for publication.

Generalitat de Catalunya (Consolidated Research Groups 2014 SGR 418 - Water and Soil Quality Unit, 2014 SGR 90 Laboratory of Toxicology and Environmental Health and 2014 SGR 934 - Chromatography. Environmental applications): Not involved in the process. 


\section{Introduction}

Priority environmental contaminants in seafood are a topic of growing interest for the scientific community and the regulatory authorities since seafood is a major dietary route for human exposure to them. These compounds include different types of pollutants among which are flame retardants (FRs).

This work was carried out in the frame of the ECsafeSEAFOOD project, which aims to assess food safety issues related to priority contaminants present in seafood as a result of environmental contamination, including those originating from harmful algal blooms and those associated with marine litter. This study addresses three specific objectives of the ECsafeSEAFOOD project, which are monitoring the presence of priority environmental contaminants in seafood, studying the effect of processing or cooking on the contaminants in seafood and performing risk assessment of the potential impact of seafood contaminants on public health.

Within the frame of the ECsafeSEAFOOD, a database of contaminants of emerging concernthe maximum levels of which are not regulated or need revision-was developed including several FRs. The selected FRs were polybrominated diphenyl ethers (PBDEs) and hexabromocyclododecane (HBCD), included in the Stockholm convention; tetrabromobisphenol A (TBBPA), included in the REACH regulation, and decabromodiphenyl ethane (DBDPE), hexabromobenzene (HBB) and 2,4,6-tribromophenol (2,4,6-TBP), highlighted by the European Food Safety Agency (EFSA) (Cruz et al., 2015, Vandermeersch et al., 2015). Pentabromoethylbenzene (PBEB), another brominated FR (BFR), halogenated norbornenes (HNs) or dechloranes, which are chlorinated FR, and methoxylated PBDEs (MeO-PBDEs), which are produced by sea organisms, were also added to the database because of their growing concern or their structural similarity to the previous FRs and their possibility of being extracted with the same method method (de la Cal et al., 2003, Labandeira et al., 2007). 
FRs are a group of compounds which are added or applied to materials to increase their fire resistance. Polybrominated diphenyl ethers (PBDEs) are the most used kind of FRs and can be found in a wide range of items such as plastics, furniture, vehicles and electronic devices (Alaee et al., 2003). PBDEs are typically produced at three different levels of bromination, that is, Penta-BDE, Octa-BDE and Deca-BDE, and classified according to their average bromine content. As PBDEs are not bonded into plastics but simply blended with the polymers, they are likely to leach out of the materials (Alaee et al., 2003) and have therefore been found in different environmental matrices such as air (Harner et al., 2006), sediment (Guerra et al., 2010b), water (Sánchez-Avila et al., 2011) and sludge (Gorga et al., 2013), as well as in biological matrices such as seafood (Lacorte et al., 2010), bird eggs (Guerra et al., 2012) and human milk (Norén and Meironyté, 2000).

PBDEs are persistent in the environment, accumulate in food chains and show toxic effects on hormonal regulation as well as neuronal, thyroid and liver activity (Branchi et al., 2003, Costa and Giordano, 2011, Mikula and Svobodova, 2006). Hence, Penta- and Octa-BDE in 2004, and Deca-BDE in 2008, were banned in the European Union (EU). In 2011, Penta- and Octa-BDE were included in the Stockholm Convention on Persistent Organic Pollutants (Convention, 2008), with exceptions for certain purposes, and their presence in formulations was reducedalso in North America - with the commitment to stop their production by the end of 2013 (Schecter et al., 2010, United States Environmental Protection Agency, 2014). The Stockholm Convention on Persistent Organic Pollutants is a global treaty to protect human health and the environment from chemicals that remain intact in the environment for long periods, become widely distributed geographically, accumulate in the fatty tissue of humans and wildlife, and have harmful impacts on human health or on the environment.

In 2010, Deca-BDE, hexabromocyclododecane (HBCD) and tetrabromobisphenol A (TBBPA) were included in the REACH regulation (Registration, Evaluation, Authorisation and Restriction 
of Chemicals) (REACH, 2006). The REACH regulation of the European Parliament and the European Council provides a legislative framework for chemicals manufacture and use in Europe. It shifts from public authorities to the industry the responsibility for ensuring that chemicals produced, imported, sold and used in the EU are safe. Among other actions, it also establishes the European Chemicals Agency (ECHA). HBCD was also included in the Stockholm Convention in 2013 limiting its application to only building materials.

Also in 2013, the directive amending Directives 2000/60/EC and 2008/105/EC as regards priority substances in the field of water policy (Directive 2013/39/EU) set environmental quality standards (EQS) in biota for some compounds (PSWP, 2013). The EQS limits of contamination were set in accordance with the Water Framework Directive (Directive 2000/60/EC) (WFD, 2000) and were generally calculated as a safety factor of 10-100 times the chronic no observed effect concentrations (NOEC) for different species including fish, daphnia or a representative organism for saline waters or algae. It is clear from their name that the EQS limits are not related to human risk, but to the state of the environment and the biota that inhabits it. The EQS limit for PBDEs (sum of congeners 28, 47, 99, 100, 153 and 154) is $0.0085 \mathrm{ng} / \mathrm{g}$ ww and the limit for HBCD is $167 \mathrm{ng} / \mathrm{g}$ ww.

$H B C D$, like PBDEs, is a brominated flame retardant (BFR) that is likely to leach out of the materials (Alaee et al., 2003) and is just as capable of long-distance transport (de Wit et al., 2006). It has also been detected in environmental, biotic and human samples (Eljarrat et al., 2004, Eljarrat et al., 2009, Guerra et al., 2010a). The technical products contain roughly 1-12 \% of each of the $\alpha$ and $\beta$ diastereoisomers, and $75-89 \%$ of the $\gamma$ diastereoisomer (Wu et al., 2012). However, the $\alpha$ diastereoisomer has the highest occurrence in food (Barghi et al., 2016).

TBBPA is used as a reactive intermediate in the production of epoxy and polycarbonate resins, where it is covalently bound and hence with limited release to the environment (Alaee et al., 
2003). However, migration of monomers of TBBPA may occur from cans coated with resins including it. As a result, TBBPA may be found in canned seafood. It is also added to some plastics and resins as a FR from where it may leach from the product to the environment (EFSA, 2011c). The occurrence of TBBPA in seafood as compiled by the European Food Safety Authority (EFSA) is with relatively few results above the detection limit.

In order to avoid these compounds, new BFRs, called emerging flame retardants (EFRs), are used as substitutes for PBDEs. The production of EFRs such as hexabromobenzene (HBB), pentabromoethylbenzene (PBEB) or decabromodiphenyl ethane (DBDPE) has increased during the last three decades and these compounds have also been included in new monitoring programs (Covaci et al., 2011). According to the REACH regulation, alternatives should hold fewer risks for the environment and human health.

DBDPE was targeted in this study because it is marketed as the alternative for Deca-BDE. PBEB and HBB were selected as they could be extracted and analysed with the same methods for sample treatment and GC-MS/MS as PBDEs and DBDPE. PBEB had its production peak in the 1970s. It is persistent in the environment and it bioaccumulates (Covaci et al., 2011). HBB is produced mainly in Japan and China, but it has been found in European sediments and fish, which proves that it can leak from the materials into the environment (Cruz et al., 2015).

Another brominated EFR is 2,4,6-tribromophenol (2,4,6-TBP) (EFSA, 2012). It may as well be formed as degradation product from other FRs such as brominated benzenes, some BDEs and TBBPA (Bergman, 1990, de Wit, 2002). Therefore, 2,4,6-TBP may occur in the marine environment through contaminated microplastics or as BFR degradation products. Besides the anthropogenic sources, natural occurrence of bromophenols in seafood may originate from algae or polychaetes, where these compounds are biosynthesized as secondary metabolites (Whitfield et al., 1999). However, information about 2,4,6-TBP is scarce and not recent. A call for data on BFRs including brominated phenols was issued by the EFSA in December 2009. 
Halogenated norbornenes (HNs)-including Dechlorane Plus (DP) and Dechlorane (Dec) 602, 603 and 604-are another type of EFR (Zhu et al., 2014). Further studies are still required to assess their behaviour and occurrence in the environment. Nonetheless, they have recently been found in matrices such as sediment (Sverko et al., 2007), air (Torre et al., 2010a), sludge (Torre et al., 2010b), water (Hong et al., 2010), seafood (Houde et al., 2014), eggs (Guerra et al., 2011) and humans (Siddique et al., 2012).

On the other hand, other brominated compounds naturally produced by sponges or red algae are present in the marine environment at levels similar to those of PBDEs, sometimes at even higher levels (Vetter et al., 2002). Methoxylated PBDEs (MeO-PBDEs) represent an example of these halogenated natural products. They have been found in several cetaceans (Alonso et al., 2014) or seafood (Losada et al., 2009) around the world. Due to their origin, MeO-PBDEs are considered as a problem only in sea waters. In fact, they can present greater levels on the high seas than on the shore (Vetter et al., 2002).

The EU Marine Strategy Framework Directive (MSFD) (Directive 2008/56/CE) establishes a framework to prevent, protect and conserve the marine environment against damaging human activities (MSFD, 2008). It sets minimum requirements for the EU countries to develop strategies to protect the marine ecosystem and to ensure economic activities linked to the marine environment are sustainable. The MSFD aims at achieving a good environmental status of the marine environment by 2020 .

This directive observes eleven qualitative descriptors for determining good environmental status. Descriptor 9 states that contaminants in seafood for human consumption cannot exceed the levels established by the existing regulations (MSFD, 2008). The MSFD group 9 compiled the regulatory levels in seafood for some substances and added a list of contaminants with no regulated limits that should also be monitored. PBDEs (the 8 congeners 
analysed in this study) and HBCD are in this list and it is recommended to analyse DBDPE and HBB too if possible (Swartenbroux et al., 2010).

The aim of this research was to evaluate the presence of PBDEs, HBCD, TBBPA, HBB, DBDPE, PBEB, 2,4,6-TBP, HNs and MeO-PBDEs in different species of seafood from all around Europe, study the effect of cooking on the concentration of these contaminants and assess the exposure and risk for humans caused by consuming seafood. Moreover, the levels were compared to the available EQS limits set by Directive 2013/39/EU in order to take into account their environmental relevance as well.

\section{Materials and methods}

\subsection{Sampling}

The criteria used for selecting the target species were the following: most common species consumed in the study area, potential to accumulate high concentrations of chemicals, wide geographic distribution, easy identification, abundance, easy capture, large enough to provide adequate tissue for analyses, found in different habitats, from extra-EU origin or from EU production and from wild or farmed origin.

A total of 42 samples of seafood consumed in Europe were collected including 10 species from the Mediterranean Sea (FAO Fishing Area 37), the North Sea (FAO Fishing Area 27 IV) and the north-east Atlantic Ocean (FAO Fishing Area 27), with 3 samples imported from the Pacific Ocean and one from India. The species were cod (3), mackerel (11), monkfish (4), mussel (10), Nile perch (1), plaice (1), salmon (3), seabream (2), shrimp (1) and tuna (6).

For mussels all edible content was sampled, for fish muscle tissue was collected without skin from the thickest part of the belly and for shrimp abdominal muscle tissue was used. The fat layer of the fish was not removed with the skin. All species were of uniform average commercial sizes and weights. 
Two samplings were carried out in April-June 2014 and September-January 2015. At each site, at least 25 specimens per species were sampled, reaching a minimum of $800 \mathrm{~g}$ of edible tissue. The pooled samples were homogenised and freeze-dried prior to shipping to the analytical laboratory. A total of 14 samples including cod (1), mackerel (3), mussel (5), plaice (1), salmon (1), seabream (1) and tuna (2) were analysed raw and cooked.

Water content in the raw samples ranged from $55.0 \%$ for a tuna sample to $87.8 \%$ for a mussel sample, whereas lipid content referenced to wet weight was between $0.03 \%$ for a mussel sample to $36.5 \%$ for a mackerel sample. Water content in the cooked samples ranged from 47.3\% for a mackerel sample to $82.7 \%$ for a mussel sample, whereas lipid content referenced to wet weight was between $0.35 \%$ for a cod sample to $28.6 \%$ for a mackerel sample. See Table 1 for further details.

Table 1. Commercial seafood from Europe sampling data

\subsection{Standards and reagents}

HBB, DBDPE, PBEB, the standard mixture of MeO-PBDEs (5-MeO-BDE-47, 6-MeO-BDE-47, 4'MeO-BDE-49, 2'-MeO-BDE-68, 5'-MeO-BDE-99, 5'-MeO-BDE-100, 4'-MeO-BDE-101 and 4'MeO-BDE-103), $\alpha-, \beta$ - and $\gamma$-HBCD, TBBPA and ${ }^{13} \mathrm{C}$-labelled standards $\alpha$-HBCD and TBBPA were purchased from Wellington Laboratories Inc. (Guelph, ON, Canada). Native and ${ }^{13} \mathrm{C}$-labelled standards mixtures of PBDEs (BDE-28, BDE-47, BDE-99, BDE-100, BDE-153, BDE-154, BDE-183 and BDE-209), syn-DP and anti-DP isomers and ${ }^{13} \mathrm{C}$-syn-DP were obtained from Cambridge Isotope Laboratories Inc. (Andover, MA, USA). Dec 602 (95\%), Dec 603 (98\%) and Dec 604 (98\%) were purchased from Toronto Research Chemical Inc. (Toronto, ON, Canada). 2,4,6-TBP was from Sigma Aldrich (Saint Louis, MO, US). Labelled compounds were used as internal standards. Al-N cartridges were provided by Biotage. Dichloromethane (DCM) and hexane, ethanol, acetic acid and sulphuric acid were purchased from Merck; acetone and methanol 
were from Rathburn, anhydrous sodium sulphate was from VWR and Milli-Q water was obtained with a Milli-Q Gradient A10 system.

\subsection{Sample preparation}

PBDE, EFR, HN and MeO-PBDE analyses were carried out using a previously optimized sample extraction method (de la Cal et al., 2003, Labandeira et al., 2007). Lyophilized sample (1.5 g) was spiked with ${ }^{13} \mathrm{C}$-PBDEs mixture and ${ }^{13} \mathrm{C}$-syn-DP. Spiked samples were kept in the fridge overnight to equilibrate. Pressurized liquid extraction (PLE) was used as extraction method using a mixture of hexane:DCM (1:1) with 2 static cycles of 10 min at $100{ }^{\circ} \mathrm{C}$ and 1500 psi. After the extraction, the lipid content was determined gravimetrically and the resulting extracts were re-dissolved in hexane and treated with concentrated sulphuric acid to remove the fat. After the acid treatment, the organic phase was cleaned by solid phase extraction (SPE) using Al- $\mathrm{N}$ cartridges $(5 \mathrm{~g})$ conditioned with hexane and eluted with hexane:DCM (1:2). Extracts were evaporated to incipient dryness and reconstituted with toluene to a final volume of $40 \mu \mathrm{l}$ prior to the instrumental analysis.

For HBCD, TBBPA and 2,4,6-TBP, lyophilised and homogenised sample (2 g) was mixed with $60 \mathrm{~g}$ of anhydrous sodium sulphate and Soxhlet extracted for $6 \mathrm{~h}$ with $150 \mathrm{ml}$ acetone:hexane (1:1). Extracts were evaporated to $10 \mathrm{ml}$, from which subsamples of $2.5 \mathrm{ml}$ were taken for gravimetrical lipid determination. The remaining extracts were evaporated and re-dissolved in a ${ }^{13} \mathrm{C}-\alpha-\mathrm{HBCD}$ internal standard solution in hexane. Then they were cleaned up with sulphuric acid and Milli-Q water. Clean extracts were evaporated and reconstituted with methanol to a final volume of $200 \mu \mathrm{l}$.

In order to evaluate the effect of processing or cooking on the contaminants in seafood, 14 samples were analysed both raw and cooked. The cooking consisted in adding culinary salt ( $2 \% \mathrm{w} / \mathrm{w}$ of edible meat) and steaming at $105^{\circ} \mathrm{C}$ wrapped in aluminium foil during 15 minutes for fish and only 5 minutes for mussels. 


\subsection{Instrumental analysis}

PBDEs, MeO-PBDEs, HBB, DBDPE and PBEB were analysed with an Agilent 7890A gas chromatograph coupled to an Agilent $7000 \mathrm{~B}$ triple quadrupole mass spectrometer. Chromatographic separation was carried out with a DB- $5 \mathrm{~ms}$ column $(15 \mathrm{~m} \times 0.25 \mathrm{~mm} \times 0.1 \mu \mathrm{m}$ of film thickness). The instrumental conditions and elution program were based on our previous works (Eljarrat et al., 2007, Eljarrat et al., 2002). For the spectrometric determination (Barón et al., 2014), electronic ionization at $300^{\circ} \mathrm{C}$ was used, with helium as carrier gas.

For the analysis of HNs (Barón et al., 2012), the chromatographic separation was carried out with another DB-5ms column. Negative chemical ionization at $175^{\circ} \mathrm{C}$ was used, with methane as ionization gas and helium as carrier gas.

On the other hand, HBCD, TBBPA and 2,4,6-TBP were analysed with an Agilent HPLC with a Kinetex C18-HPLC column ( $100 \times 2.1 \mathrm{~mm}$, particle size $2.6 \mu \mathrm{m})$ with Ultra HPLC inline filter using a gradient of methanol and $0.01 \%$ acetic acid at a flow of $0.2 \mathrm{ml} \mathrm{min}^{-1}$. Detection was carried out with a Waters Micromass Quatro ultima tandem mass spectrometer. The source temperature was $120^{\circ} \mathrm{C}$ and the desolvation temperature was $380^{\circ} \mathrm{C}$, using argon as ionization gas. The method has been validated at the Technical University of Denmark and accredited by the Danish accreditation board DANAK.

For all compounds selective reaction monitoring (SRM) mode was used with two transitions monitored for each one. The most intense transition was used for quantification and the second transition provided a confirmation comparing the $\mathrm{SRM}_{1} / \mathrm{SRM}_{2}$ ratio calculated for the standards with the ratio found in the samples. Recoveries for individual compounds ranged 51-109 \% and RSDs were 1.1-38\%. LOQs and LODs were, respectively, 7.7 pg/g lipid weight (Iw) to $35.4 \mathrm{ng} / \mathrm{g} \mathrm{Iw}$ and $2.3 \mathrm{pg} / \mathrm{g}$ Iw to $10.6 \mathrm{ng} / \mathrm{g} \mathrm{Iw}$. Quality parameters of the separate methods can be found in supplementary information (Table S1) (Barón et al., 2014). 


\subsection{Risk assessment}

\subsubsection{Concentration and consumption data}

A risk assessment was performed for a selection of contaminants for which the highest concentration levels (i.e. concentrations higher than the LOQ) and frequencies of detection were measured within this study. The selection was also based on the availability of a toxicological reference value (dose-response relationship with relevance to humans) described in literature in order to evaluate the health risk based on the exposure assessment. The selected contaminants were, therefore, BDE-47, BDE-99, TBBPA and HBCD, all of which happen to be included in the Stockholm Convention or the REACH regulation.

A database file for BDE-47, BDE-99, TBBPA and HBCD concentrations was compiled combining the primary data presented in our study with additional secondary data from peer-reviewed and grey literature (data obtained within the ECsafeSEAFOOD project) dated between 2007 and 2016 (Bakke et al., 2008, Granby, 2007, Paepke et al., 2010, Parera et al., 2013, Shanmuganathan et al., 2011, Szlinder-Richert et al., 2010, van Leeuwen and de Boer, 2008). The data include raw samples of species of commercial importance in Europe. Literature from samples outside of Europe was included to fill eventual gaps for frequently consumed species. A total of 42, 41, 39 and 27 data points were collected from literature for BDE-47, BDE-99, TBBPA and HBCD, respectively. To obtain an estimation of the contaminant intake based on the overall seafood diet, missing concentration data for frequently consumed species were completed by a mean value based on the fish group or, when applicable, based on the crustaceans and shellfish group.

In 2013, ECsafeSEAFOOD performed a consumer survey in five European countries: Belgium, Ireland, Italy, Portugal and Spain; $n=2824$ (Jacobs et al., 2015). These countries were selected to cover western, northern and southern Europe, covering a heterogeneous population in terms of seafood consumption habits. The consumer samples were nationally representative 
regarding gender, region and age within the range $18-75$ years. The consumption habits of 32 different seafood species was inquired using self-reported items. These 32 species were selected based on the consumption pattern in the five countries and on the susceptibility of the species to contain relevant concentrations of environmental contaminants. For each country, at least $85 \%$ of the total seafood diet (based on the median) is represented by the 15 most consumed species. Therefore, only the 15 most consumed species were considered for the exposure assessment. The body weight (bw) of the participants was also requested in the survey.

\subsubsection{Exposure assessment model}

For each country, a distribution was fitted to the consumption data of each species and of body weight using @RISK version 6 (Palisade Corporation, US). The seafood consumption distributions were divided by the body weight distributions, resulting in a consumption dataset (expressed in $\mathrm{kg} /(\mathrm{kg}$ bw)/day) for each country. More detailed information on the methodology and on results regarding the consumption data and body weight data is described by Jacobs et al. (2016).

To estimate the exposure to BDE-47, BDE-99, TBBPA and HBCD through the seafood diet, the consumption data of the species are combined with the concentration data of the contaminants in the samples according to formula (1):

$$
\begin{aligned}
& \text { (1) } Y_{i, c}=\sum_{v=1}^{v=15} C_{c, v} \times X_{i, v} \\
& C_{c, v}=\text { concentration of contaminant } c \text { in seafood species } v[\mu \mathrm{g} / \mathrm{kg} \mathrm{ww}] \\
& X_{i, V}=\text { consumption of seafood species } v \text { by individual }[\mathrm{kg} /(\mathrm{kg} \mathrm{bw}) / \mathrm{day}] \\
& Y_{i, c}=\text { exposure to contaminant } c \text { for individual } i[\mu \mathrm{g} /(\mathrm{kg} \mathrm{bw}) / \mathrm{day}]
\end{aligned}
$$


Note that no adjustments were made for intra-individual correlations in this aggregated exposure model, so a rough and upper bound estimation of the exposure was calculated. That is, adjustments could have been made to take into account correlations between the consumption frequencies of the different seafood species within the individual as more consumption of one specific species may imply less consumption of another. However, in this study, a generic upper bound estimation of the exposure was calculated instead.

Regarding the probabilistic exposure assessment, calculations were performed using the software package @RISK version 6 (Palisade Corporation, US) for Microsoft Excel. Best fit distributions are used for the consumption and the body weight data. Also, to take into account the variability and uncertainty in both consumption and contaminant concentration, for the concentration data a probabilistic approach is used instead of a deterministic approach (point estimate, mean value) when distribution fitting is possible and a good fit is obtained. A deterministic approach is applied on BDE-99, TBBPA and HBCD concentration data. For BDE-47, a probabilistic approach was possible for cod and herring. The mixed approach has been used before (Medeiros Vinci et al., 2012).

First order Monte Carlo simulations were performed considering 100,000 iterations to estimate BDE-47, BDE-99, TBBPA and HBCD intakes through the seafood diet for the lower and upper bound scenarios. Non-detected $(<L O D)$ were considered zero and non-quantified $(<L O Q)$ were considered as LOD (limit of detection) or LOQ (limit of quantification) for the lower bound (LB) or upper bound (UB) scenario, respectively. The estimated daily intake was expressed in $\mu \mathrm{g} /(\mathrm{kg} \mathrm{bw}) /$ day. More detailed information on the methodology regarding distribution fitting is described by Jacobs et al. (2016).

\subsubsection{Risk assessment}

To evaluate the risk for the considered population groups, no health based guidance valuesuch as a tolerable daily intake (TDI) - can be applied due to uncertainties and limitations in 
the current toxicological databases for these compounds. Instead, the EFSA Panel uses a margin of exposure (MOE) approach for the risk characterisation of exposure to these contaminants (EFSA, 2011a, b, c). The calculated MOEs are based on the lower benchmark dose limit (BMDL) value and on the estimated exposure which is included in the denominator of the formula. That is, the higher the MOE, the lower the degree of concern. However, a narrative is needed to interpret the magnitude of the MOE to evaluate the risk of the exposure. Here we consider the MOE described by the EFSA representing a low priority for risk management for the different contaminants.

For BDE-47 and BDE-99, the MOE calculation is based on a BMDL10 value (corresponding lower $95 \%$ confidence limit for a benchmark response of $10 \%$ incidence) of $309 \mu \mathrm{g} /(\mathrm{kg}$ $\mathrm{bw}) /$ day and $12 \mu \mathrm{g} /(\mathrm{kg} \mathrm{bw}) /$ day (effects on neurodevelopment as the critical endpoint), respectively. When applying EFSA's formula to calculate the MOEs, MOEs larger than 2.5 indicate that the exposure to PBDEs is unlikely to be of health concern (EFSA, 2011b). For TBBPA, a BMDL10 value of $16 \mathrm{mg} /(\mathrm{kg}$ bw)/day was identified (changes in the thyroid hormones as the critical reference point) for calculating the MOE. The default MOE value of 100 is not sufficient to cover uncertainties and variability due to deficiencies in the database. Hence, the magnitude of the resulting MOE values for TBBPA has to be critically interpreted (EFSA, 2011c). The EFSA panel identified neurodevelopmental effects on behaviour as the critical endpoint and derived a BMDL10 of $0.79 \mathrm{mg} /(\mathrm{kg} \mathrm{bw}) /$ day for HBCD. According to the methodology used by the EFSA, MOE values larger than 8 might indicate that there is no health concern when considering HBCD (EFSA, 2011a).

\section{Results and discussion}

\subsection{Contaminant levels}


Taking into account the 42 raw samples, contaminants of concern were detected in $90.5 \%$ of them with maximum concentrations ranging from $48.6 \mathrm{ng} / \mathrm{g}$ Iw for TBBPA (monkfish 04) to $356 \mathrm{ng} / \mathrm{g}$ Iw for SPBDE (seabream B1), excluding outliers. Results are summarized in Table 2 and in the SI (Table S2, all data). Only cod from the Pacific Ocean (C3), mackerel and monkfish from Portugal $(A 7,02)$ and farmed shrimp from India $(\mathrm{H} 1)$ registered $\mathrm{n}$. $d$. for all the analysed contaminants. The most occurring compounds were PBDEs, in $78.6 \%$ of the samples, and MeO-PBDEs, in $90.5 \%$ of them. HBCDs and the emerging HBB, PBEB and HNs were detected in 42.9-58.1\% of the samples; PBEB was always below its LOQ. TBBPA (only in mackerel and monkfish) and 2,4,6-TBP (only in mussel and plaice) showed frequencies of detection below $40 \%$. The emerging DBDPE was never detected.

Table 2. Contaminant levels for the raw samples (ng/g lw)

Focusing on compound families, BDE-47, BDE-99 and BDE-28, in this order, were the most occurring PBDE congeners (45.2-78.6\%), while BDE-209 was not detected. Also, $\alpha-H B C D$ was the most occurring HBCD isomer (40.5\%). Dec 604 was found only in mussel U1. 2'-MeO-BDE68 showed the highest frequency of detection at $88.1 \%$ and the other natural compounds fell lower than 35.7 \%. 5-MeO-BDE-47, 4'-MeO-BDE-49, 5'-MeO-BDE-99 and 4'-MeO-BDE-101 were always below LOQs.

\subsection{Levels compared to literature and regulation}

Comparing our PBDE levels with those of commercial samples from Valencia (western Mediterranean, Spain) purchased in the years 2007-2012 (Pardo et al., 2014), tuna, cod, monkfish and mussel show levels of the same order of magnitude with means up to $0.15 \mathrm{ng} / \mathrm{g}$ ww in the Valencian samples and up to $0.36 \mathrm{ng} / \mathrm{g} \mathrm{ww}$ (without outliers) for our work. However, Valencian salmon and mackerel were an order of magnitude below the present study, up to $0.47 \mathrm{ng} / \mathrm{g}$ ww in front of $2.80 \mathrm{ng} / \mathrm{g}$ ww. BDE-47, BDE-99 and BDE-100 were their most occurring congeners. 
In Catalan commercial samples (western Mediterranean) purchased in 2005 (Domingo et al., 2006), tuna, mackerel, salmon, mussel and shrimp revealed similar levels to our ECsafeSEAFOOD samples. However, Catalan mackerel was in the lowest half of our range (1.03-1.18 ng/g ww), while salmon was in the highest half of our range (1.72-2.34 ng/g ww).

Other results of PBDE levels in mussels in the Atlantic Ocean, the Mediterranean Sea and the North Sea match ours (Christensen and Platz, 2001, Johansson et al., 2006, Parera et al., 2013, Villaverde-de-Saa et al., 2013), but were a lot higher in the Netherlands, 2.09-12.4 ng/g ww (Van Ael et al., 2012).

Regarding the Atlantic Ocean and the North Sea, samples of shrimp, cod, mussel, mackerel, salmon had BDE-47 as the main-sometimes only-contributor to the PBDE profile in the same range as our samples (van Leeuwen and de Boer, 2008). In that study, the most contaminated specimens were mackerel ( $1 \mathrm{ng} / \mathrm{g} \mathrm{ww}$, Ireland) and salmon ( $1.6 \mathrm{ng} / \mathrm{g} \mathrm{ww}$, Scotland).

As for HBCD, the present work and all studies report predominance of the $\alpha$ isomer, as usual (EFSA, 2011a). Of our commercial samples, mackerel and mussel show the highest occurrence and concentrations of HBCDs, the rest of the samples being between $\mathrm{n}$. d. and $0.29 \mathrm{ng} / \mathrm{g} \mathrm{ww}$. A previous study with samples of the northern Atlantic Ocean and the North Sea also found higher levels in these two species, up to $2.1 \mathrm{ng} / \mathrm{g} \mathrm{ww}$, and found none in shrimp or cod (van Leeuwen and de Boer, 2008). A more recent study also shows mackerel from the Spanish area of the Atlantic Ocean with the greatest contamination by $\alpha-H B C D$ in the range $0.8-2.5 \mathrm{ng} / \mathrm{g} \mathrm{ww}$ (Lankova et al., 2013). The cited works agree on the range of concentrations for these two species and ECsafeSEAFOOD samples also fall in n.d.-5.15 ng/g ww (two outliers not considered).

Moving on to EFRs, mussels from the Italian Lake Maggiore ranged 1.1-2.9 ng/g Iw for HBB and 0.9-2.9 ng/g Iw for PBEB (Poma et al., 2014). The present study found higher levels for HBB, with $10.5 \%$ of all the samples above $29 \mathrm{ng} / \mathrm{g}$ Iw ( 3 outliers excluded) and the rest below $9 \mathrm{ng} / \mathrm{g}$ 
Iw, but PBEB concentrations were always below LOQ $(0.61 \mathrm{ng} / \mathrm{g} \mathrm{Iw})$. On the other hand, DBDPE was not detected in the mussels from the Lake Maggiore or other mussels from Spain (Villaverde-de-Saa et al., 2013). As for HNs, they were not detected or not quantifiable in this study, as they were for another Spanish study (Villaverde-de-Saa et al., 2013). Finally, the present samples are included in the range for 2,4,6-TBP that was found in three blue mussels from the Atlantic Ocean (Spain) and the North Sea (Denmark): 2.3-7.5 ng/g ww (Lankova et al., 2013). Published data for EFRs in seafood are still scarce; especially for 2,4,6-TBP, for which only the cited study was found. The data is this publication are more extensive and up-to-date. Regarding naturally-occurring MeO-PBDEs, levels in the present study ranged n.d.-305 ng/g lw, although only $11.9 \%$ of the samples showed more than $60 \mathrm{ng} / \mathrm{g} \mathrm{lw}$. However, half of the 8 congeners were always below their LOQ. This range fits the range of mussels from the Swedish Baltic Sea, in which 7 MeO-PBDEs were detected at concentrations up to $420 \mathrm{ng} / \mathrm{g} \mathrm{Iw}$ (Löfstrand et al., 2011). Also, Mediterranean mullets have similar content of MeO-PBDEs, up to $401 \mathrm{ng} / \mathrm{g}$ Iw (Ben Ameur et al., 2011). In the present and previous works, 2'-MeO-BDE-68, 6MeO-BDE-47 and 5-MeO-BDE-47 tend to be the most occurring MeO-PBDEs; the level of the latter being usually the lowest in fish. This observation was also obtained for other species such as Mediterranean tuna (Pena-Abaurrea et al., 2009).

A reasonable doubt of whether the detected methoxylated compounds derivate from already existing PBDEs might arise (Wan et al., 2009), however, 2'-MeO-BDE-68 and 6-MeO-BDE-47 have been reported to be of natural origin (Teuten et al., 2005, Vetter, 2006, Wiseman et al., 2011).

As previously mentioned, the environmental quality standards (EQS) limit set in Directive 2013/39/EU for PBDEs (sum of congeners $28,47,99,100,153$ and 154 ) is $0.0085 \mathrm{ng} / \mathrm{g} \mathrm{ww}$ and the limit for HBCD is $167 \mathrm{ng} / \mathrm{g}$ ww (PSWP, 2013). While the highest concentration of HBCDs is $41.1 \mathrm{ng} / \mathrm{g}$ ww, PBDEs were detected in $85 \%$ of the samples at $0.017-17.3 \mathrm{ng} / \mathrm{g}$ ww (mean 
$2.07 \mathrm{ng} / \mathrm{g}$ ww). With PBDE levels up to 2000 times higher than the EQS limit (240 times for the mean value), PBDEs become an important issue for the marine ecosystem, independently from the conclusions this work may drive about seafood regarding human health risks.

\subsection{Differences between species and locations}

Comparing between species, mussel is clearly the species with the highest frequency of detection for all compounds: always $80-100 \%$ and $60 \%$ only for HBB and PBEB, equalling $62.5 \%$ for tuna. Mackerel and salmon follow suit with PBDEs, HNs and MeO-PBDEs found in $87.5-100 \%$ of the specimens. It is important to note that 2,4,6-TBP was detected in all mussels and the only plaice sample but none of the other species and at concentrations $23.6-324 \mathrm{ng} / \mathrm{g}$ Iw -the same range as PBDEs.

Regarding concentrations (outliers excluded), seabream showed the highest mean values for PBDEs (179 ng/g Iw) more than doubling the other species, except for cod (107 ng/g lw). Seabream and tuna also revealed the highest means of MeO-PBDEs, 73.2 and $108 \mathrm{ng} / \mathrm{g} \mathrm{lw}$, while the rest were below $20 \mathrm{ng} / \mathrm{g} \mathrm{lw}$. Seabream also had a greater mean for HBB, $65.8 \mathrm{ng} / \mathrm{g}$ Iw, while other species had n. d.-17.6 ng/g lw.

Total HBCDs mean was equal or lower than $1.50 \mathrm{ng} / \mathrm{g}$ Iw for all species, except mackerel and mussel, with 4.64 and $14.7 \mathrm{ng} / \mathrm{g} \mathrm{Iw}$, respectively-and both with an outlier of 242 and $114 \mathrm{ng} / \mathrm{g}$ Iw. As for TBBPA, it was only detected in $40 \%$ of the mackerel and $50 \%$ of the monkfish (means 2.76 and $24.5 \mathrm{ng} / \mathrm{g} \mathrm{Iw}$ ). Although mackerels do not show the highest levels of HBCDs and TBBPA, they seem a good species to monitor these two compounds that have been recently included in the REACH regulation.

The limited toxicokinetics data suggests that, after oral administration of 2,4,6-TBP, rats rapidly absorb and eliminate it mainly via urine within two days (EFSA, 2012). Although rats might not be a suitable reference, fishes could be able to eliminate 2,4,6-TBP through their liver and 
kidneys as well, which would explain why it was not detected in most samples, but only in mussels and the plaice sample. Research into the toxicokinetics of 2,4,6-TBP in fish is required.

All taken into account a triad of species appears to make a good monitoring set: mussels due to their high occurrence for all compounds and due to their special situation with 2,4,6-TBP; seabream because of its high levels of PBDEs, HBB and MeO-PBDEs, and mackerel as it seems adequate to monitor HBCDs and TBBPA at the same time.

When samples are grouped by location (Atlantic Ocean, $n=11$; North Sea, $n=11$; Mediterranean Sea, $n=14$ ), the Mediterranean seafood shows the highest concentration for PBDEs, HBCDs and MeO-PBDEs, if always in the same order of magnitude as the two other studied locations (see figure 1). Mediterranean samples have much greater concentrations of HBB. All locations have means of PBEB and TBBPA below $1.65 \mathrm{ng} / \mathrm{g}$ lw. The North Sea has lower concentrations of 2,4,6-TBP. Finally, HNs are present in lower levels in the Mediterranean Sea. Conversely, HNs have the highest frequency of detection in this sea, together with PBDEs, HBCDs and MeO-PBDEs, all of them above $80 \%$. The Atlantic Ocean and the North Sea have frequencies below $55 \%$, except for PBDEs (63.6 and $64.3 \%$, respectively) and MeO-PBDEs (81.8 and $100 \%$ ). Altogether, the greatest difference was in the frequency of detection of PBDEs, HNs and HBCDs, which were higher in the Mediterranean Sea, where concentrations of most compounds were also a bit higher. This might be attributed to the fact that this sea is completely surrounded by civilisation, except for the Strait of Gibraltar. In fact, the North Sea samples are also a bit more contaminated than those from the Atlantic Ocean. This shows a gradation linked to how open or closed a body of water is-in terms of land surrounding it. The more surrounded by land, i.e. closed, the more polluted the samples.

Figure 1. Box plots for concentrations in raw samples from different locations (ng/g lw)

\subsection{Legacy, emerging and natural compounds}


One of the objectives of this research was to assess if the EFRs behave similarly to the wellknown legacy FRs regarding occurrence and levels. PBDEs and HBCDs were found in 78.6 and $47.6 \%$ of the samples, respectively. HBB, PBEB and HNs were found in $42.9-58.1 \%$ of them, showing occurrences similar to HBCDs. On the other hand, mean total PBDE and HBCD concentrations for all samples were 48.6 and $4.80 \mathrm{ng} / \mathrm{g}$ Iw (outliers excluded). TBBPA, HBB and HNs show similar levels to HBCDs, $3.57-8.84 \mathrm{ng} / \mathrm{g}$ lw. On the other hand, PBEB was always below LOQ and TBBPA was detected only in mackerel and monkfish.

Two special cases are DBDPE and 2,4,6-TBP. The former was not detected. The latter was detected in the only plaice sample and all the mussels. However, 2,4,6-TBP and PBDEs mean concentrations taking into account only samples with quantifiable levels are 86.5 and $76.5 \mathrm{ng} / \mathrm{g}$ Iw (or 99.1 and $83.7 \mathrm{ng} / \mathrm{g}$ Iw only looking at mussels), which should not be overlooked as monitoring this compound is a novelty.

Most EFRs seem to be as frequent as HBCDs and to be found at similar levels. The worst case scenario would be for them to follow the PBDEs pattern, but since HBCDs have also been included in the Stockholm Convention and the REACH regulation, these EFRs should be studied thoroughly. Were they proven to have negative effects on human health, their addition to the regulation should be considered.

Another aim of the research was to compare MeO-PBDEs to PBDEs. The natural compounds were found in $90.5 \%$ of the samples and the anthropogenic FRs were detected in $78.6 \%$ of them, while all other compounds were detected in $0-60 \%$ of the samples. Concentration means for all samples were also greater for MeO-PBDEs and PBDEs (28.6 and $48.6 \mathrm{ng} / \mathrm{g} \mathrm{lw}$ ) than for the rest (<9 ng/g Iw) - except for the high levels of 2,4,6-TBP, but only in mussel.

\subsection{Exposure and risk assessment}


The possible health risk from exposure to BDE-47, BDE-99, TBBPA and total HBCDs in seafood was assessed using the concentrations of the raw samples and based on the overall seafood consumption pattern of adults from Belgium, Ireland, Italy, Portugal and Spain. The results of the exposure assessment for the two scenarios (LB and UB) are summarized in the SI (Table S3). Mean values, standard deviations and the percentile P 95 of the exposure distributions are described there.

In general, adults from Portugal (PT) and Spain (ES) (southern European countries) show the highest exposure to BDE-47, BDE-99, TBBPA and HBCD through their seafood diet. Adults in these countries have a higher total seafood consumption compared to the other three countries in the study sample. The mean and P99 (high seafood consumers) exposure for the UB scenario for the country with the highest exposure are described here:

$$
\begin{aligned}
& \text { BDE-47 (PT): mean }=5.8 \times 10^{-4} \mu \mathrm{g} /(\mathrm{kg} \mathrm{bw}) / \text { day; } \mathrm{P} 99=1.4 \times 10^{-3} \mu \mathrm{g} /(\mathrm{kg} \mathrm{bw}) / \text { day } \\
& \text { BDE-99 (PT): } \text { mean }=3.5 \times 10^{-4} \mu \mathrm{g} /(\mathrm{kg} \mathrm{bw}) / \text { day; } \text { P } 99=9.9 \times 10^{-4} \mu \mathrm{g} /(\mathrm{kg} \mathrm{bw}) / \text { day } \\
& \text { TBBPA (ES): } \text { mean }=1.3 \times 10^{-3} \mu \mathrm{g} /(\mathrm{kg} \mathrm{bw}) / \text { day; } \text { P } 99=3.3 \times 10^{-3} \mu \mathrm{g} /(\mathrm{kg} \mathrm{bw}) / \text { day } \\
& \mathrm{HBCD}(\mathrm{ES}): \text { mean }=4.9 \times 10^{-4} \mu \mathrm{g} /(\mathrm{kg} \mathrm{bw}) / \text { day } ; \text { P } 99=1.1 \times 10^{-3} \mu \mathrm{g} /(\mathrm{kg} \mathrm{bw}) / \text { day }
\end{aligned}
$$

These values are several orders of magnitude below the BMDL for the critical point (Table 3).

Table 3. Exposure assessment (value of the country with the highest exposure, UB scenario) compared to the reference values

The obtained MOEs derived from the estimated exposure through the seafood diet for the different countries are provided in SI (Table S4).

The lowest estimated MOEs for BDE-47 were obtained for Portuguese adults: mean $=371, \mathrm{P} 01$ (high seafood consumers) $=119$ (UB scenario). This means that, for the five considered countries, it is unlikely that consumption of BDE-47 in seafood poses a health risk. For BDE-99, the lowest estimated MOEs were also obtained for Portugal: mean $=15, P$ o1 $=4$ (UB 
scenario). Hence, the MOEs for BDE-99 are substantially lower and approximating the threshold value of 2.5 . In fact, $0.05 \%$ of the Portuguese adult population has an estimated MOE below 2.5. In addition, aggregated exposure (including other sources) may even decrease their MOEs as other sources of exposure to PBDEs are relevant, such as meat and meat products, animal and vegetable fats and oils, milk and dairy products, eggs and egg products, products for special nutritional use or food for infants and small children (EFSA, 2011b).

Although the default MOE of 100 is insufficient to cover uncertainties and variability due to deficiencies in the toxicological database for TBBPA, our estimated MOEs are so large (several orders of magnitude) that it is unlikely that the exposure to TBBPA via seafood consumption raises a health concern for the considered population groups. Spain was the country with the highest exposure to TBBPA: mean MOE $=1.5 \times 10^{+7}, \mathrm{P} 01=4.9 \times 10^{+6}$ (UB scenario).

$\mathrm{HBCD}$ is also unlikely to pose a health risk through the seafood diet as the lowest estimated MOEs (Spanish adults, mean $=7.2 \times 10^{+3}, \mathrm{P} 01=2.7 \times 10^{+3}$ ) are also some orders of magnitude above the threshold of 8 set by the EFSA (EFSA, 2011a).

These results and conclusions are based on the available data and have to be interpreted with caution as uncertainties and limitations are involved (for details, see Jacobs et al. (2016)). However, the results indicate for which contaminants specific attention is needed and for which contaminants risk reduction measures may be appropiate. In general, the highest exposure through seafood consumption to BDE-47, BDE-99, TBBPA and HBCD was estimated for Spanish and Portuguese adults. For TBBPA and HBCD, the estimated exposure is unlikely to be of health concern, even when additional exposure is taken into account (EFSA, 2011a, c). Exposure to BDE-47 resulted in higher MOEs than the threshold MOE too; so it is unlikely that a potential risk exists. However, refined exposure assessments are recommended, including data originating from processed samples and additional sources and routes of exposures. Priority should be given to BDE-99 due to the low estimated MOEs and considering that 
cooking increases its concentration in most cases and that seafood is not the only source of exposure. Collecting more information (e.g. toxicological information or concentration in fresh and processed samples) and using more sophisticated methods (e.g. risk-benefit assessment, cumulative and aggregate exposure assessments) are recommended to refine BDE-99 exposure and risk assessment and lead to risk management strategies to reduce exposure through the seafood consumption.

\subsection{Effect of cooking}

Several studies on contaminants in seafood have enabled to estimate consumers' dietary intake levels (Domingo, 2010). Also, risk assessment and regulated limits are based on raw products although most seafood is cooked before consumption and strong variations in the concentration of contaminants occur following cooking or processing of seafood according to the cooking procedure and species (Marques et al., 2011). On the other hand, information on the effects of cooking on emerging contaminants is scarce (Domingo, 2010, Perelló et al., 2009).

Concentrations can decrease in the edible parts as a result of volatilisation or solubilisation when the fat melts or migration into the oil used for cooking. However, higher concentrations may be found because of the decrease of the weight of samples due to loss of water, volatiles, lipids, carbohydrates or proteins (Marques et al., 2011).

Cooking and processing methods differ around the world and with the food product, which hinders the inclusion of these factors in regulation. But neglecting their effect on seafood may lead to over- or underestimation of the risk for consumers and to misleading dietary advice (Houlbrque et al., 2011, Marques et al., 2011).

In our study 14 samples were analysed both raw and steamed. DBDPE, Dec 604, most MeOPBDEs (except 6-MeO-BDE-47, 2'-MeO-BDE-68 and 5'-MeO-BDE-100) and TBBPA were not 
detected in any raw or cooked sample. Looking at average variation in compound families, total PBDE levels doubled after cooking and HBB levels increased almost a third of the raw content (see figure 2). Total HBCD and MeO-PBDEs seem to behave differently depending on the species. Finally, dechloranes and 2,4,6-TBP did not seem to follow a pattern even within the same species.

Starting with PBDEs, the Atlantic cod (C1) showed the highest increase $(757 \%)$ due to a high variation of BDE-47, followed by two mussel samples (U7 306\%, U10 208\%) for which BDE209 could not be detected in the raw sample, but showed up after steaming. The rest of the samples showed level increases between 52.2 and $168 \%$, except for two mackerel samples. When present, all individual PBDEs seemed to concentrate by more than $50 \%$ during the cooking process, except BDE-99, which was also concentrated, albeit below that percentage.

The levels of the two detected brominated EFRs (HBB and PBEB) always increased after steaming; with the only exception of HBB in tuna T4 (from $0.11 \mathrm{ng} / \mathrm{g} w w$ to $\mathrm{n}$. q.). For HBB, two samples revealed increases below $20 \%$, eight were between 20 and $50 \%$ and three increased their concentration more than $50 \%$. As for PBEB, cooking allowed to quantify it in four samples with no quantifiable levels when raw $(A 3, A 10, B 1, C 1)$.

These data suggest that brominated EFRs concentrate in seafood due to the cooking process as the decade-banned PBDEs do, even if the emerging compounds show smaller increases.

MeO-PBDEs behaved similarly to the brominated EFRs in cod, mackerel, mussel and salmon. Conversely, the levels of these natural compounds dropped dramatically in seabream and tuna. HBCDs variations are also somewhat connected to the species being cooked, with increased levels for mackerel, mixed results for mussel and loss of contamination for the rest of the species. There was a tendency that cooking decrease the levels of both families (MeOPBDEs and HBCDs) in plaice, seabream and tuna, but increase their concentrations in mackerel. 
With the information extracted from our analyses no clear trend can be seen for individual $\mathrm{HBCD}$ isomers either.

Taking all this into account, our findings suggest that the steaming process concentrates most contaminants of concern, perhaps because of the aforementioned loss of weight of the samples.

Figure 2. Total PBDE concentrations in the raw and cooked sample (ng/g ww)

It would be interesting to perform a study with a greater number of cooked versus raw samples in order to confirm these trends and obtain more significant and realistic results for risk assessment.

\section{Conclusions}

Concentrations of the priority substances analysed in European seafood ranged n. d.-356 ng/g Iw and n. d.-41.1 ng/g ww. Anthropogenic PBDEs and natural MeO-PBDEs showed the highest frequencies of detection and concentrations, while HBCDs and most EFRs were found in half of the samples at similar and lower levels. DBDPE was not detected and 2,4,6-TBP was detected only in mussels but at levels comparable to those of PBDEs. Mussels and seabreams showed the highest occurrences and concentrations.

While HBCDs were below the EQS maximum limit established by Directive 2013/39/EU, PBDEs were some orders of magnitude above it. With levels up to 2000 times higher than the EQS limit, PBDEs become an important issue for the marine ecosystem.

On the other hand, the estimated human daily exposures to BDE-47, BDE-99, TBBPA and HBCDs through seafood consumption based on raw concentrations were safely below the BMDL10. Conversely, BDE-99 had an estimated MOE below the value set by the EFSA for $0.05 \%$ of Portuguese adults, which is a cause for concern. In addition to this, results suggest 
that the cooking process concentrates PBDEs and HBB in seafood; whereas HBCDs and MeOPBDEs behave differently upon cooking depending on the species.

Despite the variability in cooking procedures, the results of this study indicate the importance of considering the effect of cooking in future risk assessment and risk management using a bigger number of cooked versus raw samples.

To sum up, legacy PBDEs and their naturally produced counterparts are present in most seafood species at high levels, creating environmental concerns. HBCDs and most EFRs are not as frequent but their concentrations are not negligible. This concern does not seem to transfer to human consumption; however, the process of cooking concentrates some FRs, which might lead to a higher risk for compounds such as BDE-99. Further studies are required on the risk of cooked seafood.

\section{Acknowledgements}

The research leading to these results has received funding from the European Union Seventh Framework Programme (FP7/2007-2013) under the ECsafeSEAFOOD project (grant agreement $\mathrm{n}^{\circ}$ 311820). This work has also been partly funded by the Generalitat de Catalunya (Consolidated Research Groups 2014 SGR 418 - Water and Soil Quality Unit, 2014 SGR 90 Laboratory of Toxicology and Environmental Health and 2014 SGR 934 - Chromatography. Environmental applications). Biotage is acknowledged for SPE cartridges.

\section{References}

Alaee, M., Arias, P., Sjödin, A., Bergman, Å. 2003. An overview of commercially used brominated flame retardants, their applications, their use patterns in different countries/regions and possible modes of release. Environ. Int. 29, 683-689. Doi 10.1016/S0160-4120(03)00121-1

Alonso, M. B., Azevedo, A., Torres, J. P. M., Dorneles, P. R., Eljarrat, E., Barcelo, D., LailsonBrito, J., Maim, O. 2014. Anthropogenic (PBDE) and naturally-produced (MeO-PBDE) 
brominated compounds in cetaceans - A review. Sci. Total Environ. 481, 619-634. Doi 10.1016/j.scitotenv2014.02.022

Bakke, T., Boitsov, S., Brevik, E., Gabrielsen, G. W., Green, N., Helgason, L. B., Klungsøyr, J., Leknes, H., Miljeteig, C., Måge, A., Rolfsnes, B. E., Savinova, T., Schlabach, M., Skaare, B. B., Valdersnes, S. Norwegian Institute for Water Research (NIVA). Mapping selected organic contaminants in the Barents Sea 2007 [online]. (2008). [accessed: August 2015].

Barghi, M., Shin, E. S., Son, M. H., Choi, S. D., Pyo, H., Chang, Y. S. 2016. Hexabromocyclododecane (HBCD) in the Korean food basket and estimation of dietary exposure. Environ. Pollut. 213, 268-277. Doi 10.1016/j.envpol.2016.02.026

Barón, E., Eljarrat, E., Barceló, D. 2012. Analytical method for the determination of halogenated norbornene flame retardants in environmental and biota matrices by gas chromatography coupled to tandem mass spectrometry. J. Chromatogr. A. 1248, 154-160. Doi 10.1016/j.chroma.2012.05.079

Barón, E., Eljarrat, E., Barceló, D. 2014. Gas chromatography/tandem mass spectrometry method for the simultaneous analysis of 19 brominated compounds in environmental and biological samples. Anal. Bioanal. Chem., Doi 10.1007/s00216-014-8196-7

Ben Ameur, W., Ben Hassine, S., Eljarrat, E., El Megdiche, Y., Trabelsi, S., Hammami, B., Barcelo, D., Driss, M. R. 2011. Polybrominated diphenyl ethers and their methoxylated analogs in mullet (Mugil cephalus) and sea bass (Dicentrarchus labrax) from Bizerte Lagoon, Tunisia. Mar. Environ. Res. 72, 258-264. Doi 10.1016/j.marenvres.2011.09.009

Bergman, A. 1990. Brominated flame retardants in a global environmental perspective. Proceedings of the workshop on brominated aromatic flame retardants, Skokloster, 24-26 October 1989., Solna, National Chemicals Inspectorate (KEMI).

Branchi, I., Capone, F., Alleva, E., Costa, L. G. 2003. Polybrominated diphenyl ethers: Neurobehavioral effects following developmental exposure. NeuroToxicology. 24, 449-462. Doi 10.1016/S0161-813X(03)00020-2

Christensen, J. H., Platz, J. 2001. Screening of polybrominated diphenyl ethers in blue mussels, marine and freshwater sediments in Denmark. J. Environ. Monit. 3, 543-547. Doi 10.1039/b105501c

Convention, S. (2008). <http://chm.pops.int/> [accessed: June 2015].

Costa, L. G., Giordano, G. 2011. Is decabromodiphenyl ether (BDE-209) a developmental neurotoxicant? NeuroToxicology. 32, 9-24. Doi 10.1016/j.neuro.2010.12.010

Covaci, A., Harrad, S., Abdallah, M. A. E., Ali, N., Law, R. J., Herzke, D., de Wit, C. A. 2011. Novel brominated flame retardants: A review of their analysis, environmental fate and behaviour. Environ. Int. 37, 532-556. Doi 10.1016/j.envint.2010.11.007

Cruz, R., Cunha, S. C., Casal, S. 2015. Brominated flame retardants and seafood safety: A review. Environ. Int. 77, 116-131. Doi http://dx.doi.org/10.1016/j.envint.2015.01.001 
de la Cal, A., Eljarrat, E., Barceló, D. 2003. Determination of 39 polybrominated diphenyl ether congeners in sediment samples using fast selective pressurized liquid extraction and purification. J. Chromatogr. A. 1021, 165-173. Doi 10.1016/j.chroma.2003.09.023

de Wit, C. A. 2002. An overview of brominated flame retardants in the environment. Chemosphere. 46, 583-624. Doi http://dx.doi.org/10.1016/S0045-6535(01)00225-9

de Wit, C. A., Alaee, M., Muir, D. C. G. 2006. Levels and trends of brominated flame retardants in the Arctic. Chemosphere. 64, 209-233. Doi 10.1016/j.chemosphere.2005.12.029

Domingo, J. L. 2010. Influence of cooking processes on the concentrations of toxic metals and various organic environmental pollutants in food: A review of the published literature. Critical Reviews in Food Science and Nutrition. 51, 29-37. Doi 10.1080/10408390903044511

Domingo, J. L., Bocio, A., Falco, G., Llobet, J. M. 2006. Exposure to PBDEs and PCDEs associated with the consumption of edible marine species. Environmental Science \& Technology. 40, 4394-4399. Doi 10.1021/es060484k

EFSA. EFSA Panel on Contaminants in the Food Chain (CONTAM). Scientific opinion on hexabromocyclododecanes (HBCDDs) in food [online]. (2011a). <http://www.efsa.europa.eu/en/efsajournal/doc/2296.pdf> [accessed: August 2015].

EFSA. EFSA Panel on Contaminants in the Food Chain (CONTAM). Scientific opinion on polybrominated diphenyl ethers (PBDEs) in food [online]. (2011b). $<$ http://www.efsa.europa.eu/sites/default/files/scientific_output/files/main_documents/2156 .pdf> [accessed: March 2016].

EFSA. EFSA Panel on Contaminants in the Food Chain (CONTAM). Scientific opinion on tetrabromobisphenol A (TBBPA) and its derivatives in food [online]. (2011c). [accessed: March 2016].

EFSA. EFSA Panel on Contaminants in the Food Chain (CONTAM). Scientific opinion on brominated flame retardants (BFRs) in food: Brominated phenols and their derivatives [online]. (2012). <http://www.efsa.europa.eu/en/efsajournal/pub/2908.htm\#> [accessed: August 2015].

Eljarrat, E., De La Cal, A., Raldua, D., Duran, C., Barcelo, D. 2004. Occurrence and bioavailability of polybrominated diphenyl ethers and hexabromocyclododecane in sediment and fish from the Cinca River, a tributary of the Ebro River (Spain). Environmental Science \& Technology. 38, 2603-2608. Doi 10.1021/es0301424

Eljarrat, E., Guerra, P., Martinez, E., Farre, M., Alvarez, J. G., Lopez-Teijon, M., Barcelo, D. 2009. Hexabromocyclododecane in human breast milk: Levels and enantiomeric patterns. Environmental Science \& Technology. 43, 1940-1946. Doi 10.1021/es802919e

Eljarrat, E., Labandeira, A., Marsh, G., Raldúa, D., Barceló, D. 2007. Decabrominated diphenyl ether in river fish and sediment samples collected downstream an industrial park. Chemosphere. 69, 1278-1286. Doi 10.1016/j.chemosphere.2007.05.052 
Eljarrat, E., Lacorte, S., Barceló, D. 2002. Optimization of congener-specific analysis of 40 polybrominated diphenyl ethers by gas chromatography/mass spectrometry. Journal of Mass Spectrometry. 37, 76-84. Doi 10.1002/jms.262

Gorga, M., Martínez, E., Ginebreda, A., Eljarrat, E., Barceló, D. 2013. Determination of PBDEs, HBB, PBEB, DBDPE, HBCD, TBBPA and related compounds in sewage sludge from Catalonia (Spain). Sci. Total Environ. 444, 51-59. Doi 10.1016/j.scitotenv.2012.11.066

Granby, K., Cederberg, T. L. 2007. LC-MS/MS analysis of hexabromocyclododecane (HBCD) isomers and tetrabromobisphenol A (TBBPA) and levels in Danish fish for food consumption. The 4th International Workshop on Brominated Flame Retardants, Amsterdam.

Guerra, P., Alaee, M., Jiménez, B., Pacepavicius, G., Marvin, C., Maclnnis, G., Eljarrat, E., Barceló, D., Champoux, L., Fernie, K. 2012. Emerging and historical brominated flame retardants in peregrine falcon (Falco peregrinus) eggs from Canada and Spain. Environ. Int. 40, 179-186. Doi 10.1016/j.envint.2011.07.014

Guerra, P., Eljarrat, E., Barcelo, D. 2010a. Simultaneous determination of hexabromocyclododecane, tetrabromobisphenol $A$, and related compounds in sewage sludge and sediment samples from Ebro River basin (Spain). Anal. Bioanal. Chem. 397, 2817-2824. Doi $10.1007 / \mathrm{s} 00216-010-3670-3$

Guerra, P., Eljarrat, E., Barceló, D. 2010b. Analysis and occurrence of emerging brominated flame retardants in the Llobregat River basin. Journal of Hydrology. 383, 39-43. Doi 10.1016/j.jhydrol.2009.06.052

Guerra, P., Fernie, K., Jiménez, B., Pacepavicius, G., Shen, L., Reiner, E., Eljarrat, E., Barceló, D., Alaee, M. 2011. Dechlorane Plus and related compounds in peregrine falcon (Falco peregrinus) eggs from Canada and Spain. Environmental Science \& Technology. 45, 1284-1290. Doi 10.1021/es103333j

Harner, T., Shoeib, M., Diamond, M., Ikonomou, M., Stern, G. 2006. Passive sampler derived air concentrations of PBDEs along an urban-rural transect: Spatial and temporal trends. Chemosphere. 64, 262-267. Doi 10.1016/j.chemosphere.2005.12.018

Hong, Q. I., Liyan, L., Hongliang, J., Li, Y. I. F., Ren, N. Q. I., Hong, Y., Xinyuan, S., Lili, F., Yongsheng, D. 2010. Dechlorane plus in surficial water and sediment in a northeastern Chinese river. Environ. Sci. Technol. 44, 2305-2308. Doi 10.1021/es9027106

Houde, M., Berryman, D., de Lafontaine, Y., Verreault, J. 2014. Novel brominated flame retardants and dechloranes in three fish species from the St. Lawrence River, Canada. Sci. Total Environ. 479, 48-56. Doi 10.1016/j.scitotenv.2014.01.105

Houlbrque, F., Hervé-Fernández, P., Teyssié, J. L., Oberhaënsli, F., Boisson, F., Jeffree, R. 2011. Cooking makes cadmium contained in Chilean mussels less bioaccessible to humans. Food Chemistry. 126, 917-921. Doi 10.1016/j.foodchem.2010.11.078

Jacobs, S., Sioen, I., Pieniak, Z., De Henauw, S., Maulvault, A. L., Reuver, M., Fait, G., CanoSancho, G., Verbeke, W. 2015. Consumers' health risk-benefit perception of seafood and 
attitude toward the marine environment: Insights from five European countries. Environ. Res. 143, Part B, 11-19. Doi http://dx.doi.org/10.1016/j.envres.2015.02.029

Johansson, I., Heas-Moisan, K., Guiot, N., Munschy, C., Tronczynski, J. 2006. Polybrominated diphenyl ethers (PBDEs) in mussels from selected French coastal sites: 1981-2003. Chemosphere. 64, 296-305. Doi 10.1016/j.chemosphere.2005.12.014

Labandeira, A., Eljarrat, E., Barceló, D. 2007. Congener distribution of polybrominated diphenyl ethers in feral carp (Cyprinus carpio) from the Llobregat River, Spain. Environ. Pollut. 146, 188195. Doi 10.1016/j.envpol.2006.04.037

Lacorte, S., Ikonomou, M. G., Fischer, M. 2010. A comprehensive gas chromatography coupled to high resolution mass spectrometry based method for the determination of polybrominated diphenyl ethers and their hydroxylated and methoxylated metabolites in environmental samples. J. Chromatogr. A. 1217, 337-347. Doi 10.1016/j.chroma.2009.11.024

Lankova, D., Kockovska, M., Lacina, O., Kalachova, K., Pulkrabova, J., Hajslova, J. 2013. Rapid and simple method for determination of hexabromocyclododecanes and other LC-MS-MSamenable brominated flame retardants in fish rapid detection in food and feed. Anal. Bioanal. Chem. 405, 7829-7839. Doi 10.1007/s00216-013-7076-x

Löfstrand, K., Liu, X. T., Lindqvist, D., Jensen, S., Asplund, L. 2011. Seasonal variations of hydroxylated and methoxylated brominated diphenyl ethers in blue mussels from the Baltic Sea. Chemosphere. 84, 527-532. Doi 10.1016/j.chemosphere.2011.01.001

Losada, S., Roach, A., Roosens, L., Santos, F. J., Galceran, M. T., Vetter, W., Neels, H., Covaci, A. 2009. Biomagnification of anthropogenic and naturally-produced organobrominated compounds in a marine food web from Sydney Harbour, Australia. Environ. Int. 35, 1142-1149. Doi 10.1016/j.envint.2009.07.008

Marques, A., Lourenço, H. M., Nunes, M. L., Roseiro, C., Santos, C., Barranco, A., Rainieri, S., Langerholc, T., Cencic, A. 2011. New tools to assess toxicity, bioaccessibility and uptake of chemical contaminants in meat and seafood. Food Research International. 44, 510-522. Doi 10.1016/j.foodres.2010.12.003

Medeiros Vinci, R., Jacxsens, L., Van Loco, J., Matsiko, E., Lachat, C., de Schaetzen, T., Canfyn, M., Van Overmeire, I., Kolsteren, P., De Meulenaer, B. 2012. Assessment of human exposure to benzene through foods from the Belgian market. Chemosphere. 88, 1001-1007. Doi http://dx.doi.org/10.1016/j.chemosphere.2012.03.044

Mikula, P., Svobodova, Z. 2006. Brominated flame retardants in the environment: Their sources and effects (a review). Acta Vet. BRNO. 75, 587-599. Doi 10.2754/avb200675040587

MSFD. Directive 2008/56/EC of the European Parliament and of the Council of 17 June 2008 establishing a framework for community action in the field of marine environmental policy (Marine Strategy Framework Directive) [online]. (2008). <http://eur-lex.europa.eu/legalcontent/EN/TXT/?uri=CELEX:32008L0056> [accessed: April 2016]. 
Norén, K., Meironyté, D. 2000. Certain organochlorine and organobromine contaminants in Swedish human milk in perspective of past 20-30 years. Chemosphere. 40, 1111-1123. Doi 10.1016/S0045-6535(99)00360-4

Paepke, O., Petersen, M., Ebsen, P., Neugebauer, F., Opel, M. 2010. Brominated Flame Retardants in European Food Samples Collected in 2007 to 2009.

Pardo, O., Beser, M. I., Yusà, V., Beltrán, J. 2014. Probabilistic risk assessment of the exposure to polybrominated diphenyl ethers via fish and seafood consumption in the Region of Valencia (Spain). Chemosphere. 104, 7-14. Doi http://dx.doi.org/10.1016/j.chemosphere.2013.12.084

Parera, J., Abalos, M., Santos, F. J., Galceran, M. T., Abad, E. 2013. Polychlorinated dibenzo-pdioxins, dibenzofurans, biphenyls, paraffins and polybrominated diphenyl ethers in marine fish species from Ebro River Delta (Spain). Chemosphere. 93, 499-505. Doi 10.1016/j.chemosphere.2013.06.022

Pena-Abaurrea, M., Weijs, L., Ramos, L., Borghesi, N., Corsolini, S., Neels, H., Blust, R., Covaci, A. 2009. Anthropogenic and naturally-produced organobrominated compounds in bluefin tuna from the Mediterranean Sea. Chemosphere. 76, 1477-1482. Doi 10.1016/j.chemosphere.2009.07.004

Perelló, G., Martí-Cid, R., Castell, V., Llobet, J. M., Domingo, J. L. 2009. Concentrations of polybrominated diphenyl ethers, hexachlorobenzene and polycyclic aromatic hydrocarbons in various foodstuffs before and after cooking. Food Chem. Toxicol. 47, 709-715. Doi http://dx.doi.org/10.1016/j.fct.2008.12.030

Poma, G., Binelli, A., Volta, P., Roscioli, C., Guzzella, L. 2014. Evaluation of spatial distribution and accumulation of novel brominated flame retardants, HBCD and PBDEs in an Italian subalpine lake using zebra mussel (Dreissena polymorpha). Environ. Sci. Pollut. Res. 21, 96559664. Doi 10.1007/s11356-014-2826-7

PSWP. Directive 2013/39/EU of the European Parliament and of the Council of 12 August 2013 amending Directives 2000/60/EC and 2008/105/EC as regards priority substances in the field of water policy [online]. (2013). <http://eur-lex.europa.eu/legalcontent/en/ALL/?uri=CELEX\%3A32013L0039> [accessed: April 2016].

REACH. Regulation (EC) No 1907/2006 of the European Parliament and of the Council of 18 December 2006 concerning the Registration, Evaluation, Authorisation and Restriction of Chemicals (REACH), establishing a European Chemicals Agency, amending Directive 1999/45/EC and repealing Council Regulation (EEC) No 793/93 and Commission Regulation (EC) No 1488/94 as well as Council Directive 76/769/EEC and Commission Directives 91/155/EEC, 93/67/EEC, 93/105/EC and 2000/21/EC [online]. (2006). <http://eur-lex.europa.eu/legalcontent/EN/TXT/?uri=CELEX:32006R1907> [accessed: August 2015].

Sánchez-Avila, J., Fernandez-Sanjuan, M., Vicente, J., Lacorte, S. 2011. Development of a multiresidue method for the determination of organic micropollutants in water, sediment and mussels using gas chromatography-tandem mass spectrometry. J. Chromatogr. A. 1218, 67996811. Doi 10.1016/j.chroma.2011.07.056 
Schecter, A., Haffner, D., Colacino, J., Patel, K., Päpke, O., Opel, M., Birnbaum, L. 2010. Polybrominated diphenyl ethers (PBDEs) and hexabromocyclodecane (HBCD) in composite U.S. food samples. Environ. Health Perspect. 118, 357-362. Doi 10.1289/ehp.0901345

Shanmuganathan, D., Megharaj, M., Chen, Z., Naidu, R. 2011. Polybrominated diphenyl ethers (PBDEs) in marine foodstuffs in Australia: Residue levels and contamination status of PBDEs. Marine Pollution Bulletin. 63, 154-159. Doi http://dx.doi.org/10.1016/j.marpolbul.2011.06.002

Siddique, S., Xian, Q., Abdelouahab, N., Takser, L., Phillips, S. P., Feng, Y.-L., Wang, B., Zhu, J. 2012. Levels of dechlorane plus and polybrominated diphenylethers in human milk in two Canadian cities. Environ. Int. 39, 50-55. Doi 10.1016/j.envint.2011.09.010

Sverko, E., Tomy, G. T., Marvin, C. H., Zaruk, D., Reiner, E., Helm, P. A., Hill, B., McCarry, B. E. 2007. Dechlorane Plus levels in sediment of the lower Great Lakes. Environmental Science \& Technology. 42, 361-366. Doi 10.1021/es0710104

Swartenbroux, F., Albajedo, B., Angelidis, M., Aulne, M., Bartkevics, V., Besada, V., Bignert, A., Bitterhof, A., Hallikainen, A., Hoogenboom, R., Jorhem, L., Jud, M., Law, R., Licht Cederberg, D., McGovern, E., Miniero, R., Schneider, R., Velikova, V., Verstraete, F., Vinas, L., S., V. Piha, H. MARINE STRATEGY FRAMEWORK DIRECTIVE Task Group 9 Contaminants in fish and other seafood [online]. (2010). <http://mcc.jrc.ec.europa.eu/documents/201406241428.pdf> [accessed: April 2016].

Szlinder-Richert, J., Barska, I., Usydus, Z., Grabic, R. 2010. Polybrominated diphenyl ethers (PBDEs) in selected fish species from the southern Baltic Sea. Chemosphere. 78, 695-700. Doi http://dx.doi.org/10.1016/j.chemosphere.2009.12.004

Teuten, E. L., Xu, L., Reddy, C. M. 2005. Two Abundant Bioaccumulated Halogenated Compounds Are Natural Products. Science. 307, 917-920. Doi 10.1126/science.1106882

Torre, A. D. I., Pacepavicius, G., Shen, L., Reiner, E., Jimenez, B., Alaee, M., Martinez, M. A. 2010a. Dechlorane plus and related compounds in Spanish air. Organohalogen Compound. 72, 929-932.

Torre, A. D. I., Shen, L., Reiner, E., Jimenez, B., Alaee, M., Martinez, M. A. 2010b. New halogenated norbornene flame retardants in sewage sludge. Organohalogen Compound. 72, 1060-1063.

United States Environmental Protection Agency. 2014. An alternative assessment for the flame retardant decabromodiphenyl ether (DecaBDE). Doi

Van Ael, E., Covaci, A., Blust, R., Bervoets, L. 2012. Persistent organic pollutants in the Scheldt estuary: Environmental distribution and bioaccumulation. Environ. Int. 48, 17-27. Doi 10.1016/j.envint.2012.06.017

van Leeuwen, S. P. J., de Boer, J. 2008. Brominated flame retardants in fish and shellfish levels and contribution of fish consumption to dietary exposure of Dutch citizens to HBCD. Molecular Nutrition \& Food Research. 52, 194-203. Doi 10.1002/mnfr.200700207 
Vandermeersch, G., Lourenço, H. M., Alvarez-Muñoz, D., Cunha, S., Diogène, J., Cano-Sancho, G., Sloth, J. J., Kwadijk, C., Barcelo, D., Allegaert, W., Bekaert, K., Fernandes, J. O., Marques, A., Robbens, J. 2015. Environmental contaminants of emerging concern in seafood - European database on contaminant levels. Environ. Res. 143, Part B, 29-45. Doi http://dx.doi.org/10.1016/j.envres.2015.06.011

Vetter, W. 2006. Marine halogenated natural products of environmental relevance. In: Reviews of Environmental Contamination and Toxicology, Vol 188. Springer, New York, pp. 157. Doi 10.1007/978-0-387-32964-2_1

Vetter, W., Stoll, E., Garson, M. J., Fahey, S. J., Gaus, C., Muller, J. F. 2002. Sponge halogenated natural products found at parts-per-million levels in marine mammals. Environ. Toxicol. Chem. 21, 2014-2019. Doi 10.1002/etc.5620211002

Villaverde-de-Saa, E., Valls-Cantenys, C., Quintana, J. B., Rodil, R., Cela, R. 2013. Matrix solidphase dispersion combined with gas chromatography-mass spectrometry for the determination of fifteen halogenated flame retardants in mollusks. J. Chromatogr. A. 1300, 8594. Doi 10.1016/j.chroma.2013.05.064

Wan, Y., Wiseman, S., Chang, H., Zhang, X., Jones, P. D., Hecker, M., Kannan, K., Tanabe, S., Hu, J., Lam, M. H. W., Giesy, J. P. 2009. Origin of hydroxylated brominated diphenyl ethers: Natural compounds or man-made flame retardants? Environmental Science \& Technology. 43, 75367542. Doi 10.1021/es901357u

WFD. Directive 2000/60/EC of the European Parliament and of the Council of 23 October 2000 establishing a framework for Community action in the field of water policy [online]. (2000). <http://faolex.fao.org/docs/pdf/eur23005.pdf> [accessed: April 2016].

Whitfield, F. B., Helidoniotis, F., Shaw, K. J., Svoronos, D. 1999. Distribution of bromophenols in species of marine algae from eastern Australia. J. Agric. Food Chem. 47, 2367-2373. Doi 10.1021/jf981080h

Wiseman, S. B., Wan, Y., Chang, H., Zhang, X. W., Hecker, M., Jones, P. D., Giesy, J. P. 2011. Polybrominated diphenyl ethers and their hydroxylated/methoxylated analogs: Environmental sources, metabolic relationships, and relative toxicities. Marine Pollution Bulletin. 63, 179-188. Doi 10.1016/j.marpolbul.2011.02.008

Wu, T., Wang, S., Huang, H., Zhang, S. 2012. Diastereomer-specific uptake, translocation, and toxicity of hexabromocyclododecane diastereoisomers to maize. J. Agric. Food Chem. 60, 85288534. Doi 10.1021/jf302682p

Zhu, B., Lai, N. L. S., Wai, T.-C., Chan, L. L., Lam, J. C. W., Lam, P. K. S. 2014. Changes of accumulation profiles from PBDEs to brominated and chlorinated alternatives in marine mammals from the South China Sea. Environ. Int. 66, 65-70. Doi 10.1016/j.envint.2014.01.023 
Table 1. Commercial seafood from Europe sampling data

\begin{tabular}{|c|c|c|c|c|c|c|}
\hline sample & species & $\begin{array}{l}\text { sampling } \\
\text { period }^{\mathrm{a}}\end{array}$ & sampling site & $\begin{array}{l}\text { raw or } \\
\text { cooked }\end{array}$ & $\begin{array}{c}\text { water } \\
(\%)^{b}\end{array}$ & fat $(\%)^{b}$ \\
\hline \multirow[t]{2}{*}{$\mathrm{C} 1$} & cod Atlantic & II & Denmark & cooked & 75.7 & 0.35 \\
\hline & & & & raw & 81.0 & 0.24 \\
\hline $\mathrm{C} 2$ & cod Atlantic & I & North Sea & raw & 81.7 & 0.46 \\
\hline C3 & cod Pacific & 1 & Pacific & raw & 82.0 & 0.41 \\
\hline $\mathrm{A} 1$ & mackerel & 1 & Italy & raw & 74.8 & 3.44 \\
\hline $\mathrm{A} 2$ & mackerel & 1 & Denmark & raw & 63.9 & 13.5 \\
\hline \multirow[t]{2}{*}{ A3 } & mackerel & II & Denmark & cooked & 47.3 & 28.6 \\
\hline & & & & raw & 57.1 & 36.5 \\
\hline A4 & mackerel & I & Channel & raw & 67.6 & 9.64 \\
\hline A5 & mackerel & I & North Sea & raw & 75.7 & 2.10 \\
\hline A6 & mackerel & 1 & Spain & raw & 68.2 & 12.7 \\
\hline A7 & mackerel canned & 1 & Portugal & raw & 63.3 & 10.6 \\
\hline A8 & mackerel canned & II & Portugal & raw & 57.7 & 10.9 \\
\hline \multirow{2}{*}{ A9 } & mackerel fresh & II & Spain & cooked & 65.0 & 11.6 \\
\hline & & & & raw & 70.2 & 7.93 \\
\hline \multirow[t]{2}{*}{ A10 } & mackerel fresh & II & Italy & cooked & 53.8 & 9.20 \\
\hline & & & & raw & 63.2 & 7.87 \\
\hline A11 & mackerel fresh & II & North Sea & raw & 64.2 & 12.6 \\
\hline O1 & monkfish large & I & Portugal & raw & 84.4 & 0.26 \\
\hline $\mathrm{O} 2$ & monkfish small & 1 & Portugal & raw & 84.3 & 0.23 \\
\hline $\mathrm{O} 3$ & monkfish large & II & Portugal & raw & 80.9 & 0.17 \\
\hline $\mathrm{O} 4$ & monkfish small & II & Portugal & raw & 79.7 & 0.25 \\
\hline U1 & mussel & 1 & Denmark & raw & 86.2 & 0.03 \\
\hline U2 & mussel & I & Netherlands & raw & 81.2 & 0.61 \\
\hline \multirow[t]{2}{*}{ U3 } & mussel & II & Italy & cooked & 76.6 & 2.12 \\
\hline & & & & raw & 82.1 & 0.57 \\
\hline U4 & mussel & I & Italy & raw & 86.0 & 1.54 \\
\hline U5 & mussel & II & Denmark & raw & 84.9 & 1.29 \\
\hline \multirow[t]{2}{*}{ U6 } & mussel & II & France & cooked & 70.2 & 2.89 \\
\hline & & & & raw & 75.3 & 2.12 \\
\hline \multirow[t]{2}{*}{ U7 } & mussel & II & Netherlands & cooked & 77.0 & 2.17 \\
\hline & & & & raw & 79.2 & 1.93 \\
\hline \multirow[t]{2}{*}{ U8 } & mussel & II & Ireland & cooked & 82.7 & 1.79 \\
\hline & & & & raw & 87.8 & 0.81 \\
\hline U9 & mussel & 1 & Spain & raw & 78.3 & 0.48 \\
\hline \multirow[t]{2}{*}{ U10 } & mussel & II & Spain & cooked & 80.7 & 1.43 \\
\hline & & & & raw & 85.3 & 0.91 \\
\hline N1 & Nile perch & 1 & Lake Victoria & raw & 77.7 & 2.35 \\
\hline \multirow[t]{2}{*}{$\mathrm{P} 1$} & plaice small & II & North Sea & cooked & 77.6 & 1.07 \\
\hline & & & & raw & 81.1 & 0.79 \\
\hline \multirow[t]{2}{*}{ L1 } & salmon Norwegian & II & Denmark & cooked & 63.1 & 13.2 \\
\hline & & & & raw & 59.3 & 20.3 \\
\hline
\end{tabular}




\section{ACCEPTED MANUSCRIPT}

\begin{tabular}{lllllll} 
L2 & salmon Norwegian farmed & I & Denmark & raw & 59.3 & 17.3 \\
L3 & salmon Scottish farmed & I & Netherlands & raw & 57.7 & 14.5 \\
\hline B1 & seabream & II & other & cooked & 70.7 & 3.68 \\
& & & & raw & 78.5 & 2.94 \\
B2 & seabream farmed & I & Greece & raw & 75.7 & 1.39 \\
\hline H1 & shrimp farmed & I & India & raw & 79.2 & 0.56 \\
\hline T1 & tuna canned & I & Portugal & raw & 62.9 & 10.5 \\
T2 & tuna canned & II & Portugal & raw & 55.0 & 12.7 \\
T3 & tuna imported large & II & Pacific & cooked & 67.6 & 4.42 \\
& & & & raw & 56.2 & 4.85 \\
T4 & tuna imported small & II & Pacific & cooked & 68.6 & 3.61 \\
& & & & raw & 64.6 & 2.79 \\
T5 & tuna Pacific large & I & Mediterranean & raw & 78.0 & 0.43 \\
T6 & tuna Pacific small & I & Mediterranean & raw & 70.4 & 0.57 \\
\hline
\end{tabular}

a Sampling periods: I = April-June 2014, II = September-January 2015

${ }^{\mathrm{b}}$ Referenced to wet weight 
Table 2. Contaminant levels for the raw samples (ng/g lw)

\begin{tabular}{|c|c|c|c|c|c|c|c|c|c|c|}
\hline species & & ¿PBDEs & HBB & PBEB & DBDPE & $\sum \mathrm{HNs}$ & ¿MeO-PBDEs & $\sum$ HBCDs & TBBPA & 2,4,6-TBP \\
\hline cod & mean & 107 & 10.7 & n. q. $^{a}$ & n. d. ${ }^{a}$ & 72.9 & 1.73 & 1.50 & n. d. & n. d. \\
\hline \multirow{2}{*}{$n=3$} & range & n. d.-317 & n. d.-31.8 & n. d.-n. q. & - & n. d.-146 & n. d. -4.55 & n. d. -4.41 & - & - \\
\hline & freq. of det. & 66.7 & 33.3 & 33.3 & 0.0 & 50.0 & 66.7 & 33.3 & 0.0 & 0.0 \\
\hline mackerel & mean $^{b}$ & 42.6 & 0.68 & n. q. & n. d. & 5.98 & 19.8 & 4.64 & 2.76 & n. d. \\
\hline \multirow[t]{3}{*}{$n=11$} & range $^{b}$ & n. d. -188 & n. d. -1.55 & n. d.-n. q. & - & n. d. -26.5 & n. d. -56.7 & n. d. -21.3 & n. d. -6.56 & - \\
\hline & freq. of det. & 90.9 & 36.4 & 36.4 & 0.0 & 87.5 & 90.9 & 54.5 & 40.0 & 0.0 \\
\hline & outlier $^{c}$ & 220 & $70.1 ; 84.1$ & - & - & 78.1 & - & 242 & - & - \\
\hline monkfish & mean & 57.7 & 17.6 & n. q. & n. d. & n. d. & n. q. & n. d. & 24.5 & n. d. \\
\hline \multirow[t]{2}{*}{$n=4$} & range & n. d. -151 & n. d. -40.4 & n. d.-n. q. & - & - & n. d.-n. q. & - & n.d. -48.6 & - \\
\hline & freq. of det. & 50.0 & 50.0 & 50.0 & 0.0 & 0.0 & 75.0 & 0.0 & 50.0 & 0.0 \\
\hline mussel & mean $^{b}$ & 52.7 & 2.76 & n. q. & n. d. & 8.90 & 13.0 & 14.7 & n. d. & 99.1 \\
\hline \multirow[t]{3}{*}{$n=10$} & range $^{b}$ & $6.10-141$ & n. d. -5.81 & n. d.-n. q. & - & $0.22-44.2$ & n. q. -44.2 & n.d.-54.4 & - & $38.9-176$ \\
\hline & freq. of det. & 100.0 & 60.0 & 60.0 & 0.0 & 87.5 & 100.0 & 80.0 & 0.0 & 100.0 \\
\hline & outlier ${ }^{c}$ & 362 & 562 & - & - & 6941 & $224 ; 280$ & 114 & - & 324 \\
\hline Nile perch & $\mathrm{n}=1$ & n. d. & n. d. & n. d. & n. d. & n. d. & n. $q$. & n. d. & n. a. & n. a. \\
\hline plaice & $\mathrm{n}=1$ & 55.3 & 8.61 & n. q. & n. d. & n. d. & n. q. & 1.45 & n. d. & 23.6 \\
\hline salmon & mean & 10.3 & n. d. & n. q. & n. d. & 0.48 & 6.16 & 0.33 & n. d. & n. d. \\
\hline \multirow[t]{2}{*}{$n=3$} & range & $3.98-18.0$ & - & n. d.-n. q. & - & n.d.-0.96 & n. q. -12.9 & n. d. -0.88 & - & - \\
\hline & freq. of det. & 100.0 & 0.0 & 30.0 & 0.0 & 100.0 & 100.0 & 30.0 & 0.0 & 0.0 \\
\hline seabream & mean & 179 & 65.8 & n. q. & n. d. & n. d. & 73.2 & n. d. & n. d. & n. d. \\
\hline \multirow[t]{2}{*}{$n=2$} & range & $2.94-356$ & n.d.-131 & n. d.-n. q. & - & - & n. q. -144 & - & - & - \\
\hline & freq. of det. & 100.0 & 50.0 & 50.0 & 0.0 & 0.0 & 100.0 & 0.0 & 0.0 & 0.0 \\
\hline shrimp & $n=1$ & n. d. & n. d. & n. d. & n. d. & n. d. & n. d. & n. a. & n. a. & n. a. \\
\hline tuna & mean & 7.4 & 1.23 & n. q. & n. d. & 1.35 & 108 & 0.19 & n. d. & n. d. \\
\hline \multirow[t]{2}{*}{$n=6$} & range & n. d. -38.0 & n. d. -3.24 & n. d.-n. q. & - & n.d. -5.38 & n. q. -305 & n. d. -0.87 & - & - \\
\hline & freq. of det. & 62.5 & 62.5 & 62.5 & 0.0 & 25.0 & 100.0 & 16.7 & 0.0 & 0.0 \\
\hline \multirow[t]{3}{*}{ total $n=42$} & freq. of det. & 78.6 & 42.9 & 50.0 & 0.0 & 58.1 & 90.5 & 47.6 & 15.0 & 35.0 \\
\hline & LOD & 10.6 & 0.20 & 0.18 & 9.66 & 0.02 & 3.75 & 2.0 & 0.84 & 8.41 \\
\hline & $\mathrm{LOQ}$ & 35.4 & 0.67 & 0.61 & 32.2 & 0.07 & 12.5 & 4.4 & 2.80 & 23.0 \\
\hline
\end{tabular}

${ }^{a}$ n. d. = below LOD; n. q. = below LOQ 
${ }^{b}$ Outliers not included

'Outliers calculated for $n>6$ as values above Q3 +1.5 IQR (Q3 = third quartile, IQR = interquartile range)

Table 3. Exposure assessment (value of the country with the highest exposure, UB scenario) compared to the reference values

\begin{tabular}{|c|c|c|c|c|c|c|c|c|}
\hline compound & BMDL10 & BMDL critical point & $\begin{array}{l}\text { country with the } \\
\text { highest exposure }\end{array}$ & $\begin{array}{c}\text { mean exposure } \\
\mu \mathrm{g}(\mathrm{kg} \mathrm{bw})^{-1} \mathrm{day}^{-1}\end{array}$ & $\begin{array}{l}\text { threshold } \\
\text { MOE }\end{array}$ & $\begin{array}{l}\text { mean } \\
\mathrm{MOE}\end{array}$ & $\begin{array}{l}\text { P } 05 \\
\text { MOE }\end{array}$ & $\begin{array}{l}\text { P } 01 \\
\text { MOE }\end{array}$ \\
\hline BDE-47 & $309 \mu \mathrm{g}(\mathrm{kg} \mathrm{bw})^{-1} \mathrm{day}^{-1}$ & neurodevelopment & Portugal & $5.8 \mathrm{E}-4$ & 2.5 & 371 & 158 & 119 \\
\hline BDE-99 & $12 \mu \mathrm{g}(\mathrm{kg} \mathrm{bw})^{-1} \mathrm{day}^{-1}$ & neurodevelopment & Portugal & $3.5 \mathrm{E}-4$ & 2.5 & 15 & 6 & $4 *$ \\
\hline TBBPA & $16 \mathrm{mg}(\mathrm{kg} \mathrm{bw})^{-1} \mathrm{day}^{-1}$ & thyroid hormones & Spain & $1.3 \mathrm{E}-3$ & 100 & $1.5 \mathrm{E}+7$ & $6.7 E+6$ & $4.9 \mathrm{E}+6$ \\
\hline HBCDs & $0.79 \mathrm{mg}(\mathrm{kg} \mathrm{bw})^{-1} \mathrm{day}^{-1}$ & neurodevelopment & Spain & $4.9 \mathrm{E}-4$ & 8 & $7.2 \mathrm{E}+3$ & $3.4 \mathrm{E}+3$ & $2.7 \mathrm{E}+3$ \\
\hline
\end{tabular}

${ }^{*} 0.05 \%$ of the Portuguese adult population has an estimated MOE lower than 2.5 


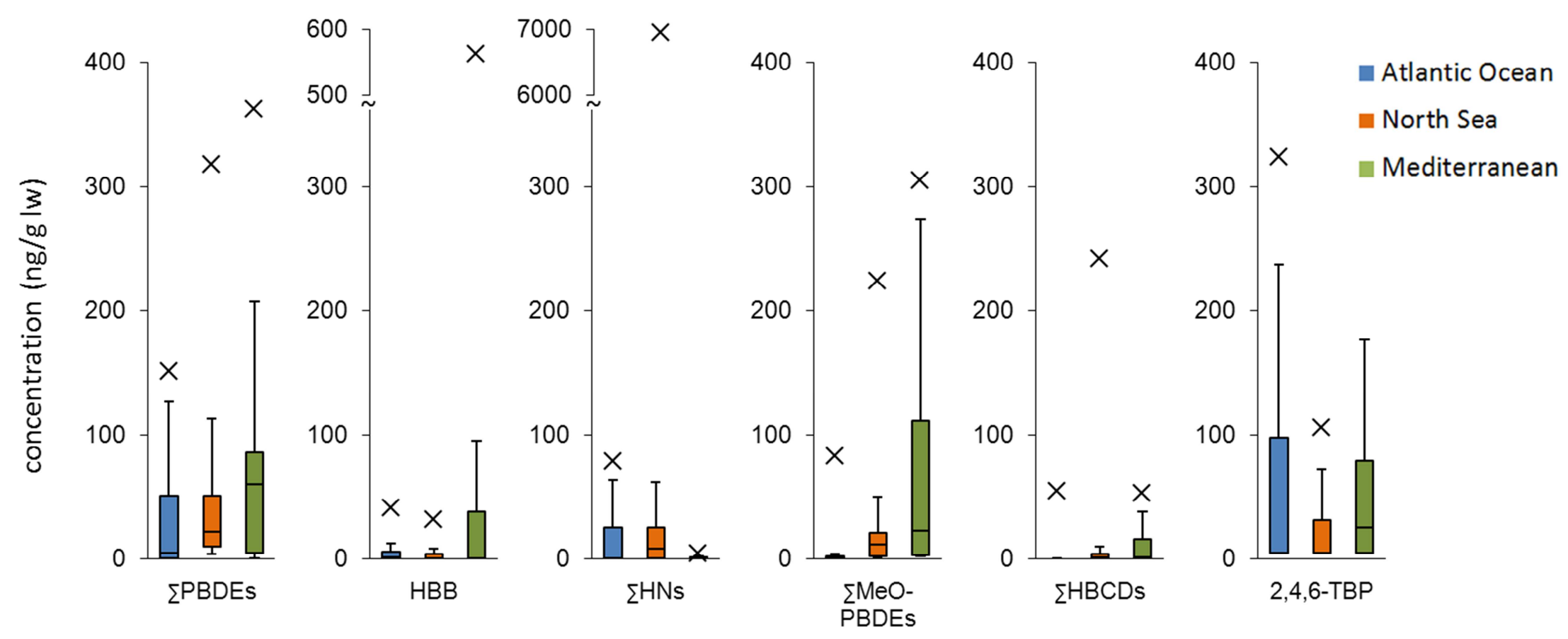

Figure 1. Box plots for concentrations in raw samples from different locations (ng/g lw) 

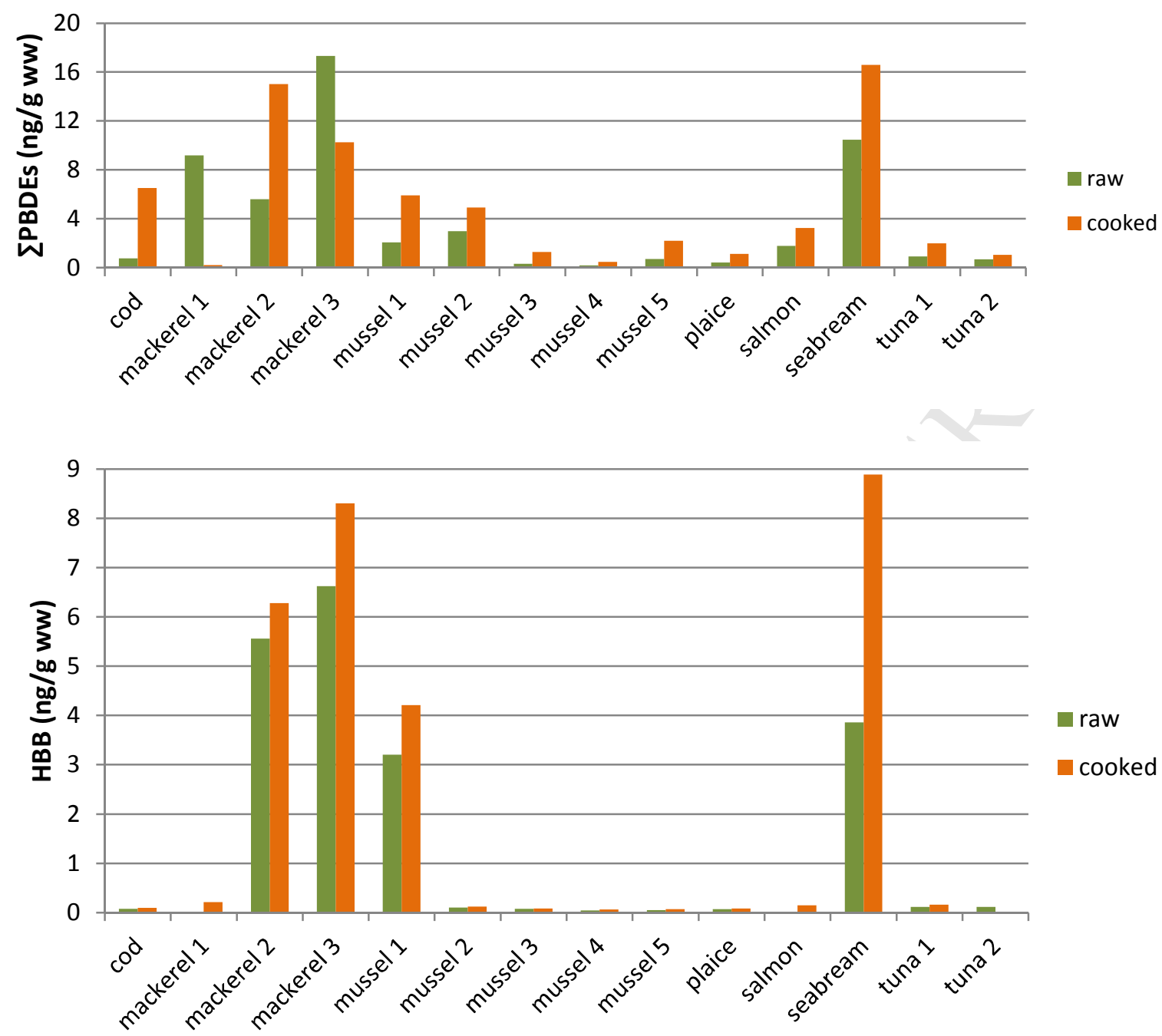

Figure 2. Total PBDE and HBB concentrations in the raw and cooked sample (ng/g ww) 